\title{
Thumbscrews for Agencies or for Individuals? How to Reduce Unemployment
}

\author{
Andrey Launov ${ }^{(*)}$ and Klaus Wälde $e^{(*), 1}$ \\ ${ }^{(*)}$ University of Mainz, Université catholique de Louvain and CESifo
}

September 2013

\begin{abstract}
To which extent does an increase in operating effectiveness of public employment agencies on the one hand and a reduction of unemployment benefits on the other reduce unemployment? Using the recent labour market reform in Germany as background we find that the role of unemployment benefit reduction for the reduction of unemployment is very modest (7\% of the observed decline). Enhanced effectiveness of public employment agencies, to the contrary, explains a substantial part $(34 \%)$ of the observed post-reform unemployment decline. If disincentive effects of PEA reforms had been avoided, the effect could have increased to $51 \%$.
\end{abstract}

JEL Codes: E24, J65, J68

Keywords: Employment agencies, unemployment benefits

labour market reform, unemployment, structural model

\footnotetext{
${ }^{1}$ Both authors are at the Gutenberg School of Management and Economics, University of Mainz, JakobWelder-Weg 4, 55131 Mainz, Germany. Fax + 49.6131.39-23827. andrey.launov@uni-mainz.de, phone + 49.6131.39-23233. waelde@uni-mainz.de,www.waelde.com, phone + 49.6131.39-20143. We are grateful to seminar participants in Mainz, participants of the SaM Annual Conference in Mainz, workshops and conferences in Hamburg and Paris (Sciences Po), to Christian Holzner, Philipp Kircher, Francis Kramarz, Michael Krause, Tom Krebs, Bruno van der Linden, Thomas Rothe, Eric Smith and Gianluca Violante for very useful discussions and comments and to Sylwia Bialek for excellent research assistance. Special thanks go to Fred Henneberger for his invaluable guidance in understanding the juridical aspects of labour market policy.
} 


\section{Introduction}

Understanding the determinants of unemployment has always been at the center of economic research and public interest alike. This is true in "old times" when oil price shocks hit OECD countries, just as much as today in the aftermath of the financial crisis.

It is widely accepted by now that labour market institutions such as unemployment benefit system, trade unions, minimum wages, employment protection legislation and labour taxes stand among the key determinants of unemployment in OECD countries (see e.g. Blau and Kahn, 1999, and Nickell and Layard, 1999). Despite their apparent heterogeneity, all of these institutions have one salient trait in common: whatever the degree of coordination frictions, they shape the incentives of the market participants. Just in contrast to that stands another important labour market institution: public employment agency. Whatever the incentives of the market participants, public employment agencies reduce the degree of coordination frictions (Petrongolo and Pissarides, 2001).

While the employment effects of unemployment benefits, unions, employment protection and taxation have been quite extensively studied to this date, there is surprisingly little evidence on the role of public employment agencies (PEAs) in reducing equilibrium unemployment. The purpose of the present paper is to fill this gap.

Using the unique setup of a German labour market reform that came into vigour between 2003 and 2005, we quantify the effect of a reform-induced increase in operating effectiveness of the Federal Employment Agency (a PEA) on the observed post-reform decline of the aggregate unemployment rate. We furthermore compare the increase in operating effectiveness of this PEA with the reduction of generosity of unemployment benefits, the latter being likewise a part of the reform. We find that organizing the work of PEAs in a more efficient way has scored much better than creating pecuniary incentives through unemployment benefits. In fact, re-organization of the agency accounts for about $34 \%$ of the observed unemployment decline, while benefit reduction barely adds another $7 \%$.

While developing our argument, we also discover that an increase in effectiveness of a PEA need not always lead to a reduction of unemployment. In fact, a heterogeneous increase of productivity of various divisions of a PEA (e.g. divisions for short-term vs. divisions for long-term unemployed workers) implies disincentive effects and may actually increase unemployment. This sounds like a paradox (reminding of the 'immiserizing growth' literature in international trade, see Bhagwati, 1958) but an intuitive explanation can be provided: The disincentive effect arises for short-term unemployed workers whenever search productivity of long-term unemployed workers goes up. When a reform of a PEA implies that much more care will be taken of long-term unemployed workers, an increase in the search productivity of long-term unemployed workers results. As a consequence, their exit rate tends to go up. The short-term unemployed anticipate this increase in the exit rate and therefore have less incentives to search intensively while being short-term unemployed. Search effort and exit rates of the short-term unemployed go down. As long as the disincentive effect for the short-term unemployed is stronger than the positive effect on the exit rate for the long-term unemployed workers, the unemployment rate rises.

This paradox goes beyond a theoretical curiosity as it has immediate policy implications: If differences in unemployment duration are not due to observable characteristics (i.e. they result from pure chance), policy reforms should be homogenous. While unemployment in 
Germany due to the PEA reform did actually decrease, the decrease could have been much larger if the PEA reform had been more homogeneous. We estimate that it could have accounted for up to $51 \%$ of the observed decrease instead of the actual $34 \%$.

To reach our conclusions, we build on the search and matching model of Launov and Wälde (2013). Our model shares a number of elements with the existing search and matching literature. Workers are ex-ante heterogeneous in skills, as in Mortensen and Pissarides (1999) and Postel-Vinay and Robin (2002), and ex-post heterogeneous in duration of their unemployment spells. The model allows for time-dependent unemployment benefits, as in Albrecht and Vroman (2005) and Coles and Masters (2006), to capture the differences between unemployment insurance (UI) and unemployment assistance (UA) payments. Benefits are proportional to past wages, as in Chéron and Langot (2010), and there is a fixed time limit on UI. Workers optimally choose search effort, as in Cahuc and Lehmann (2000) and Lehmann and van der Linden (2007), and experience negative duration dependence of their exit rates out of unemployment due to Bayesian learning. Our extension of Launov and Wälde (2013) consists in allowing for reforms of PEAs leading to homogenous and heterogeneous increases in matching productivity for short- and long-term unemployed workers. An increase in productivity of long-term unemployed workers exceeding the one for short-term unemployed workers leads to the disincentive effect for short-term unemployed workers which in turn can lead to an increase in the unemployment rate.

We quantify this model using the estimates from the existing literature as well as our own estimates of the structural parameters. The reduced-form literature provides parameters that allow computing the change in the number of matches that has been induced by the reform of the PEA. ${ }^{2}$ We use the structure of our model to establish the link between these reducedform estimates and the primitive parameters responsible for matching productivity of the PEA in our equilibrium matching model. Effectively this allows to recover the structural form from a reduced form. The appropriate reduced-form estimates are provided by Klinger and Rothe (2012). Our own estimates of structural parameters come from Launov and Wälde (2013). With these we simulate, both simultaneously and independently, the response of the equilibrium unemployment rate to the increase in the effectiveness of the PEA and to the reduction of unemployment benefit generosity.

The closest papers to ours in the structural literature on PEAs comprise Pissarides (1979), Fougère et al. (2009) and Jung and Kuhn (2013). Pissarides (1979) considers a theoretical equilibrium search model with two types of search channels. Unemployed workers can either obtain job offers via a PEA or via a PEA and through private search. Both search channels are costly to the unemployed worker. A match via a PEA is also costly to a firm. Pissarides shows that reducing costs charged by the PEA to the firm discourages private search. The resulting increase in matches through the agency and reduction of matches through private search lead to an ambiguous effect on the aggregate unemployment rate.

Left aside for years, the topic has been re-addressed for the first time by Fougère et al. (2009). In a one-sided job search model, Fougère et al. (2009) study optimal private search effort when the PEA provides job offers at an exogenous arrival rate and when private search costs are given by a constant plus some variable cost component. As in Pissarides

\footnotetext{
${ }^{2}$ The conceptual framework for reduced-form estimation of matching productivity of the agency is the empirical model of Coles and Smith (1998) and Gregg and Petrongolo (2005).
} 
this implies that an increase in the productivity of a PEA can increase or decrease the expected exit rate from unemployment. Setting up a structural estimation of their model with French data, they find that more productive PEAs unambiguously increase the exit rate from unemployment.

As we do not allow for private search in our setup, we abstract from this PissaridesFougère-Pradel-Roger effect. By allowing for heterogenous productivity changes for shortand long-term unemployed workers, we also obtain this at first sight paradoxical effect. We see our intertemporal channel, where short-term unemployed workers anticipate higher exit rates for the state of being long-term unemployed, as complementary to theirs. Going beyond these two papers, we quantify equilibrium effects of a reform of a PEA (that actually took place in practice) on the unemployment rate and emphasize the importance of PEAs relative to changes in unemployment benefits.

In a somewhat different vein from the above two papers, Jung and Kuhn (2013) consider the effectiveness of a PEA in matching unemployed with vacant jobs to argue that too low effectiveness of the PEA in Germany largely explains the difference in "ins" and "outs" of unemployment between Germany and the US in 80s and 90s. This indirectly supports the reform of the PEA addressed in our paper, with Jung and Kuhn (2013) calling for evaluation of the equilibrium effect of this reform. We provide such an evaluation and show that the reform has indeed contributed to the reduction of the unemployment rate substantially. ${ }^{3}$

Our paper is further related to three different strands of the applied literature that deals with labour market policies and institutions. First, we add to the fairly rich structural literature on the quantification of the employment effects of institutions. To give just a few recent examples from this literature, Pries and Rogerson (2005) and Yashiv (2004) simulate the impact of a wide array of institutions, such as unemployment insurance, hiring subsidy, labour taxes and minimum wages, on the equilibrium unemployment rate. Addressing single institutions, Cahuc and Malherbet (2004) calibrate the employment effect of the experience-rated system of financing unemployment benefits. Immervoll et al. (2007) perform microsimulations on the influence of in-work benefits and L'Haridon and Malherbet (2009) look into the effect of employment protection through layoff tax and payroll subsidy. Boeri and Burda (2009) investigate the impact of endogenous coverage of collective bargaining and Bentolila et al. (2012) assess the role of temporary contracts and firing costs. Finally, Flinn (2006) provides a structural estimation of the employment effect of a minimum wage policy and Launov and Wälde (2013) do the same for the length and level of unemployment benefits. We contribute to this literature by evaluating - as we show - a tremendously important institution which, surprisingly, has been largely overlooked so far. This institution is the employment agency itself.

Second, we add to the existing reduced-form econometric literature on the effectiveness of PEAs as compared to other search methods. This literature predominantly follows the pioneering contributions of Holzer (1988) and Blau and Robins (1990). It considers a multitude of job search techniques of unemployed workers, such as search through the agency

\footnotetext{
${ }^{3}$ Other more distantly related papers include Plesca (2010), who sets up a general equilibrium model with directed search through agencies. In addition, a literature emerges that deals with equilibrium consequences of particular aspects of PEAs activity. One known to us example is Cahuc and Le Barbanchon (2010) who quantify the employment effect of counselling. Lastly, agencies may be viewed as middlemen (see e.g. Yavaş, 1994).
} 
itself, search through friends or relatives, direct application without referral, search through advertisements and so on. It investigates the contribution of PEAs to generating contacts with firms and to generating job offers (and acceptance of the latter) that come out of such contacts. Conclusions on the effectiveness of the agency in performing these tasks vary. ${ }^{4} \mathrm{Ir}-$ respective of the conclusions, the reduced-form nature of this literature makes it hard to infer about the effect of PEAs on the equilibrium unemployment rate. We contribute to this literature by looking beyond the simple significance of the agency and estimate its equilibrium impact on the dynamics of unemployment.

Third, we add to the debate on the impact of reduced benefit generosity on the unemployment rate in Germany. Predictions on the true size of this impact vary tremendously in the literature. In the first three years after the reform, just right before the onset of the Great Recession, the observed unemployment rate has declined by about 3.9 percentage points. At the highest extreme, Krause and Uhlig (2012) find that reduced generosity alone has led to a fall of the unemployment rate by as much as 2.8 percentage points, explaining over $2 / 3$ of the observed decline. A somewhat more conservative value of a 1.4 percentage point reduction is reported by Krebs and Scheffel (2013). At the lowest extreme, Launov and Wälde (2013) find that the reduction of benefits is responsible for less than 0.1 percentage points of the decrease of the unemployment rate, explaining almost nothing of the post-reform change in unemployment. With a fair degree of precision we replicate the extreme and intermediate results above and explain their nature. We show that large effects in the literature hinge on assumptions about the direct effect of UA benefits reduction. Using estimates of the direct effect that is consensual in the empirical literature, our final conclusion is that only 0.3 percentage points of the reduction of the unemployment rate can be attributed to the reduced generosity. Surprisingly, it was the reform of the PEA rather than the reform of the benefit system, that has indeed reduced the unemployment rate.

The paper is organized as follows. Section 2 presents an overview and background of recent labour market reforms in Europe aimed at tackling rising unemployment. It also presents stylized facts about German unemployment and provides detailed description of the comprehensive labour market reform of 2003-2005 (the so-called Hartz reform). Section 3 describes the model we use to reach all our conclusions. Here we also address the ambiguity of the impact of the reform of a PEA under heterogeneous increase of effectiveness for short- and long-term unemployed workers and present the assessment strategy tailored specifically to the purposes of this paper. Section 4 analyses the effects of improving a PEA and of reducing unemployment benefits on aggregate unemployment. Section 5 explains why different studies on the impact of reducing unemployment benefits lead to different results and outlines the way of reconciling them. Section 6 concludes.

\footnotetext{
${ }^{4}$ See Weber and Mahringer (2008) for the most recent application and summary of this literature over the preceding twenty years. The most notable recent contribution outside this summary is Graversen and van Ours (2008).
} 


\section{European unemployment and reforms}

\subsection{Reforms in European countries}

Rising and persistent unemployment in Europe has a long history. Recent theory (Ljungqvist and Sargent, 1998; 2008) identifies the interaction of shocks and generous labour market institutions of a welfare state as a primary reason for such phenomenal dynamics. In this theory generous unemployment benefits prevent laid-off workers from quickly accepting jobs where new skills need to be developed, while at the same time old skills become gradually obsolete with the change of economic environment induced by the shock. As a result structural unemployment accumulates, adding to higher persistence, and unemployment rate keeps going up.

Consistent with this theory European governments have responded with reducing generosity of benefit systems, with Sweden (Carling et al., 2001), Denmark (Geerdsen, 2006), the UK (Petrongolo, 2009) and Norway (Røed and Westlie, 2012) being notable examples, among others. Gradually reducing benefits has brought a good deal of success in some of the countries, as for instance in the Netherlands and the UK (Nickell and van Ours, 2000). Nevertheless, this success was far from being shared by all other economies.

\subsection{Hartz reforms in Germany}

\subsubsection{Stylized facts}

Germany is no exception among its European neighbours. Since early 1970s it has experienced a steady increase in unemployment, peaking in March 2005 and calling for restructuring of the (supposedly) generous institutions of the welfare state.

The long awaited political response has arrived in early 2000s with a comprehensive labor market reform: the Hartz reform. The reform has been introduced step by step between 2003 and 2005. It consisted of four different packages (Hartz I to IV) which affected nearly all aspects of the German labour market. Remarkable about the structure of the reform is that its third package (Hartz III) was almost exclusively devoted to reshaping operational regulations of the Federal Employment Agency (a PEA), while its last package (Hartz IV) focused almost exclusively on the monetary compensation scheme for the unemployed workers.

By simply looking at the data the Hartz reform appears to have contributed positively to the reduction of the unemployment rate. Figure 1 shows the dynamics of monthly unemployment rate between January 2001 and December 2008. One can see that after a relatively stable phase of 2001 to 2004 a strong decline has emerged starting from 2005. This applies both to Germany as a whole (left panel) and to East and West Germany separately (right panel). The most intriguing message of this figure, though, is that the beginning of the fall of unemployment coincides with the date Hartz IV legally came into effect. In terms of numbers, within three years after the introduction of Hartz IV the unemployment rate in Germany has gone down from $11.71 \%$ in 2005 to $7.80 \%$ in 2008 , i.e. by 3.91 percentage points. The same applies to East and West Germany with 5.57 and 3.45 percentage points reduction, respectively. 

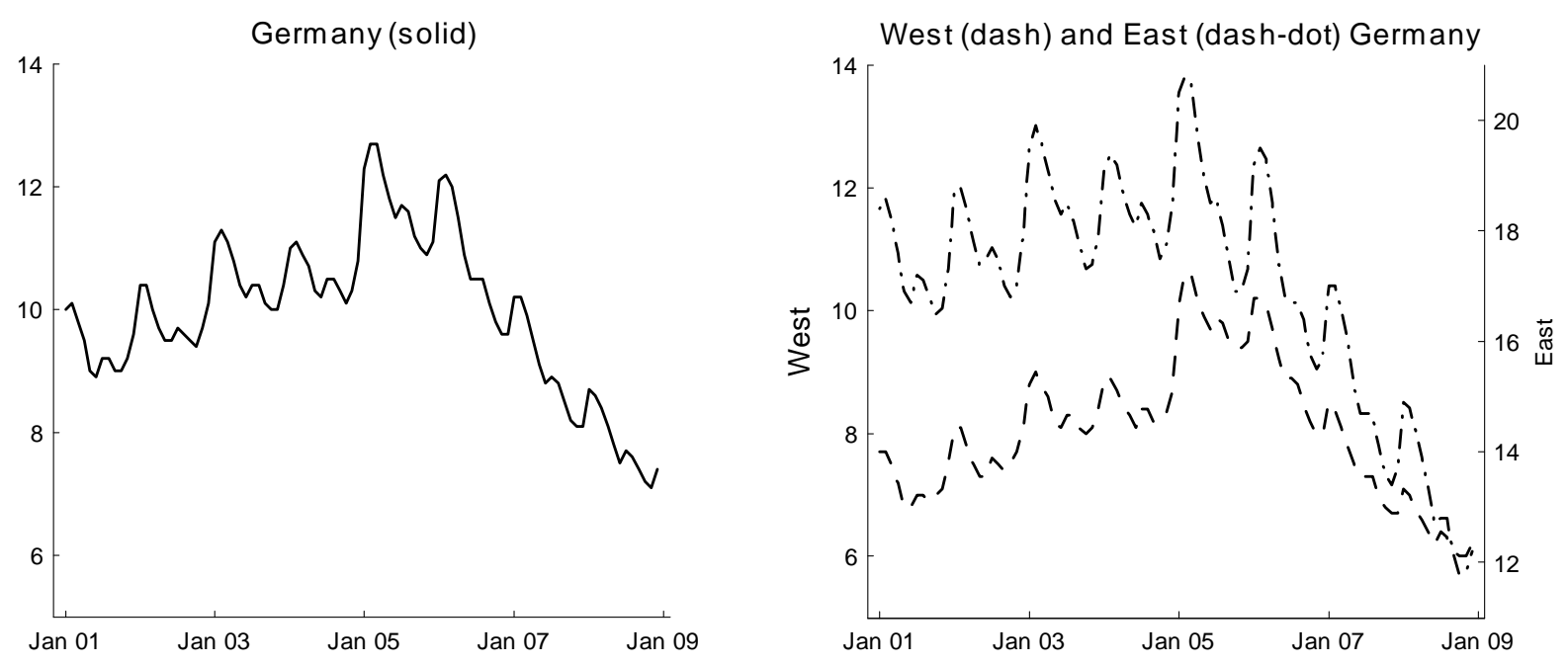

Figure 1 Monthly unemployment rate around the time of the Hartz reforms (data source: Bundesagentur für Arbeit)

It would be tempting to state that the unemployment benefit reform under arrangements of Hartz IV has become a turning point in tackling unemployment. Yet, temporal coincidence does not imply causality. As it takes time for a PEA to adjust to new rules under arrangements of Hartz III, the drop in unemployment could actually be the result of a more effective PEA, or of any other measure of the Hartz reforms. Hence, the actual contribution of Hartz IV, of Hartz III and indeed of any other Hartz package, is far from being clear. Providing the clarification is the raison d'être of the present paper.

\subsubsection{Institutional framework of the reform}

The Hartz reform has been designed to substantially refurbish the institutional organization of the German labour market. To give a clear idea of what is the place of the two institutions of our interest (PEA and unemployment benefits) in the entire set of policy measures foreseen by the reform, here is a brief overview of all its core packages (for details on the corresponding literature, see app. 7.2.).

Hartz I has launched a variety of employment-stimulating programmes and flexible forms of work. It has also established personnel service agencies which would serve as intermediaries between job searchers and employers, coordinating loan work placement. It has furthermore introduced training vouchers to take advantage of occupational training and implemented special rules for job market integration of workers over 50 years of age. On top of that, Hartz I has strengthened sanctions in case of voluntary job quits, rejection of suitable offers and aborting training programmes and/or temporary work placement. This package has become effective as of January 2003.

Hartz II has developed new rules for so-called "mini-" and "midijobs". Workers in minijobs were allowed to earn up to EUR 400 tax-free per month. A linear tax rule was introduced for midijobs paying up to EUR 800 per month. Hartz II has also modified the 
program for start-up subsidies to enhance transitions to self-employment. It became effective simultaneously with Hartz I.

Hartz III has laid out the internal administrative reform of the Federal Employment Agency - a PEA responsible for processing all claims by unemployed - as an entity. It has brought in a set of new regulations and revised distribution of responsibilities within the agency. Most importantly, it has created a special division - a "Job Center" - as a unified address for benefit claimants. Creation of job centers allowed to increase contact time per unemployed worker and provide specialized advice for the long-term unemployed. This part of the reform has also reduced the weight of active labour market policies. Hartz III has become effective as of January 2004.

Hartz IV has abolished the proportionality of the former UA benefits to the previous net earnings. A fixed UA benefit (called Arbeitslosengeld II; ALG II) was introduced instead, low enough to generate a reduction of assistance payments on average. It has furthermore reduced the duration of entitlement to UI benefits (the latter now called Arbeitslosengeld I; ALG I) for workers over 45. The severity of this reduction of the entitlement length is increasing with age. This package has become effective as of January 2005.

This overview shows why this reform can be used to estimate the effects of a reform of PEAs on the one hand and to compare it to the effect of a reform of unemployment benefit systems. The third package, i.e. Hartz III, can almost completely be attributed to the reform of the PEA. While there were some sanction mechanisms introduced under Hartz III, they are negligible in duration. ${ }^{5}$ Further, the implementation of Hartz III took place in January 2004 where no other policy change was implemented. Due to this uniqueness in design and timing, we identify the effect of a PEA reform by analysing the effect Hartz III on the German labour market.

Similarly, it is easy to see that the reduction of unemployment benefit generosity was the central objective of the fourth package (Hartz IV). As these regulations were implemented in January 2005, there is a sufficiently large distance from the implementation of Hartz III (and also the earlier reforms). Thus, the nature and timing of the reform clearly identifies the intervention into the PEA (as an increase in matching effectiveness of the agency) and intervention into benefit system (as a reduction of unemployment benefit generosity) in our structural analysis to follow.

It should be noted that there were also elements of PEA improvements, namely the introduction of personnel service agencies and strengthening of sanctions, in the first package of the Hartz reforms. However PEA-related components of Hartz I were only a small fraction of the entire package and the composition of Hartz I is too complex to allow identification of these components within the entire spectrum of the package policies. For this reason we will take a conservative stance and measure the effect of the reform of the PEA by the effect of Hartz III exclusively.

We are also aware of the fact that any implementation of a reform is not instantaneous but that there is rather some transition phase. Given the nature of the estimates we are going to employ (see further below), we can identify the permanent long-run effect of the PEA reform and the permanent effect of the unemployment benefit reform.

\footnotetext{
${ }^{5}$ Benefits can be revoked for one week if an individual fails to appear and for two weeks if an individual does not display enough commitment.
} 


\section{The model and assessment strategy}

\subsection{The model}

We formulate a Mortensen-Pissarides matching model with time-dependent unemployment benefit payments. Workers in our model are risk averse and ex ante heterogeneous with respect to observed skill distribution and unobserved search productivity distribution. Firms operate within skill-specific markets, each opening a vacancy for a particular skill level. Wages are set by collective bargaining and the government runs the budget by financing unemployment benefits through the labour tax. We base our analysis on an extended version of Launov and Wälde (2013). The theoretical extension consists in allowing for homogenous and heterogeneous reforms of public employment agencies. We capture this by exogenous increases in search productivities that can differ between short-term and long-term unemployed workers. This yields the productivity paradox and provides the framework to compare the effects of reforms of PEAs to reforms of unemployment benefit payments.

Equilibrium in our model is defined by a set of skill-specific triples comprising wage, unemployment rate and labour market tightness, such that optimality conditions for the worker and firm behaviour are satisfied and the government budget is balanced. Aggregation with respect to skills provides the economy-wide equilibrium unemployment rate.

- Unemployment benefit system

We explicitly formalize the statutory two-step unemployment compensation system with UI benefits $\left(b_{U I}\right)$, UA benefits $\left(b_{U A}\right)$ and the time limit on UI benefits. Let $s$ denote the duration of unemployment and let $\bar{s}$ denote the duration of entitlement to UI benefits. The benefit system in our model is given by

$$
b(s)=\left\{\begin{array}{l}
b_{U I}, \text { for } 0 \leq s \leq \bar{s} \\
b_{U A}, \text { for } s>\bar{s}
\end{array}\right.
$$

where $b_{U I}>b_{U A}$. This system reflects both pre- and post-Hartz IV institutional environments. Before the reform, both $b_{U I}$ and $b_{U A}$ are proportional to the net wage paid by the last job, after the reform $b_{U A}$ is replaced by the fixed ALG II amount.

Eligibility to UA benefits is means tested, with $\pi^{U A}$ denoting the individual's probability (for the econometrician) of passing the means test. As means tests relate to family income and further individual circumstances which are usually known to workers beforehand, workers know with certainty whether they will pass this test.

- Workers

Workers are ex ante heterogeneous with respect to skills and search productivity. The skill distribution $\{\pi(k)\}_{k=1}^{K}$ takes $K$ distinct levels and is known to the worker upon entry into the market. The distribution of search productivity takes two distinct levels: 'low' and 'high', where $\pi^{\chi}$ is the population share of high-productive workers. The worker does not know with certainty, how productive she is in search. Instead, at the beginning of each unemployment spell she has a prior belief about being a high-productive type. We denote 
this subjective probability by $p(0)$. This belief is subject to Bayesian updating throughout the unemployment spell as described in (5) below.

Unemployed workers of skill $k$ receive benefits $b(s)$ and exert search effort $\phi_{k}(s)$ to look for jobs. Instantaneous utility of unemployment $v\left(b(s), \phi_{k}(s)\right)$ strictly increases in benefits and strictly decreases in effort, as search brings disutility. We assume that the instantaneous utility function takes a CRRA form, $v\left(b(s), \phi_{k}(s)\right)=\frac{1}{1-\sigma}\left[b(s)^{1-\sigma}-1\right]-\phi_{k}(s)$.

While search effort brings disutility, it also increases the chances of contact with a vacancy available on the corresponding skill market. Contacts with firms arrive to workers at the objective rate

$$
\mu_{k}(s, \chi)=\left((1-\chi) \eta_{0, k}+\chi \eta_{1, k}\right) \psi(s)\left[\phi_{k}(s) \theta_{k}\right]^{\alpha}, \quad \eta_{1}>\eta_{0}
$$

where $\chi$ is an indicator variable that takes the value of 1 if the worker is high-productive in search (and $\chi=0$ if low-productive) and where $\theta_{k}$ denotes the tightness of the market for skill $k$, i.e. the number of vacancies divided by the number of unemployed of skill group $k$. The parameter $\psi(s)$ is a productivity parameter of the PEA that equals unity before the Hartz reform. It takes a value larger than one (the exact magnitude of which should be determined empirically) after the reform. Due to the institutional arrangement of the particular reform of the PEA under consideration, the value the productivity parameter of the PEA will differ between short-term $\left(\psi^{U I}\right)$ and long-term unemployed workers $\left(\psi^{U A}\right)$ which requires the dependence on unemployment duration $s$.

Since unemployed workers do not know their search productivity type with certainty, their subjectively perceived contact rate is given by $\mu_{k}(s, p(s))=\eta(s) \psi(s)\left[\phi_{k}(s) \theta_{k}\right]^{\alpha}$, where $\eta(s)=(1-p(s)) \eta_{0}+p(s) \eta_{1}$ is the probabilistic description of their perceived type. Upon successful contact with a firm, unemployed workers get a job that pays the net wage $w_{k}$.

Let $V_{k}(b(s), s)$ denote the value of unemployment at unemployment duration $s$ in skill group $k$ given the unemployment benefit $b(s)$. Furthermore, let $V\left(w_{k}\right)$ denote the value of a job at wage $w_{k}$. Unemployed workers choose search effort $\phi_{k}(s)$ to maximize their value of unemployment given their subjective probability of being a high-productive searcher. The Bellman equation for the value of unemployment reads

$\rho V_{k}(b(s), s)=\max _{\phi_{k}(s)}\left\{v\left(b(s), \phi_{k}(s)\right)+\frac{d}{d s} V_{k}(b(s), s)+\mu_{k}(s, p(s))\left[V\left(w_{k}\right)-V_{k}(b(s), s)\right]\right\}$,

where $\rho$ is the rate of time preference. The first component under the max-operator shows the instantaneous utility of unemployment net of search costs. The second component is the deterministic change in the value of unemployment due to anticipation of the expiration of entitlement to UI and due to changes in the subjective probability of being high-productive in search. The last component is the expected gain form the transition to employment.

Given our specification of the instantaneous utility function $v($.$) shown just before (2)$ and the specification of the subjective arrival rate shown just after (2), optimal effort is determined by the first-order condition to (3),

$$
\phi(s)=\left\{\alpha \eta(s) \psi(s) \theta^{\alpha}[V(w)-V(b(s), s)]\right\}^{1 /(1-\alpha)} .
$$


The belief $p(s)$ of being high-productive in search falls over time,

$$
\frac{d}{d s} p(s)=-p(s)(1-p(s))\left[\mu_{k}(s, 1)-\mu_{k}(s, 0)\right]<0,
$$

reflecting Bayesian updating of prior beliefs which takes into account the fact that the individual has not yet found a job. The longer the duration in unemployment, the less the individual believes to be good at searching for a job.

Once employed, individuals of skill type $k$ receive the net wage $w_{k}$ and do not search for jobs anymore, enjoying the utility $v\left(w_{k}\right)=\frac{1}{1-\sigma}\left[w_{k}^{1-\sigma}-1\right]$. The worker-firm match is destroyed at the exogenous rate $\lambda_{k}$. Whenever loosing the job, an individual starts the new unemployment spell with a restored full entitlement to UI benefits. Consequently, the Bellman equation for the value of employment reads

$$
\rho V\left(w_{k}\right)=v\left(w_{k}\right)+\lambda_{k}\left[V_{k}(b(0), 0)-V\left(w_{k}\right)\right] .
$$

The first component on the right hand side shows the instantaneous utility of employment and the second component reflects the capital loss due to job destruction.

The solution to the worker's problem is the optimal path of search effort, $\phi_{k}(s)$. This path is determined by two forces: the known time limit to UI at $\bar{s}$ and Bayesian updating of individual beliefs. Depending on which force is stronger the path can either have an inverted $\mathrm{U}$ shape or decrease monotonically with time, both being determined by the size of $b_{U I}$ and $b_{U A}$. This solution is fundamentally different from the constant endogenous search effort level in a Mortensen-Pissarides setup without the known time limit to UI benefits and/or Bayesian updating.

- Firms

A worker-firm pair on the skill market $k$ produces output $A_{k}$. Firms pay the gross wage $w_{k}^{\text {gross }}=w_{k} /(1-\kappa)$, where $\kappa$ is the tax rate to finance unemployment benefits. Let $J\left(w_{k}\right)$ denote the value of a producing firm and let $J_{0 k}$ denote the value of the vacant firm on the corresponding skill market. Then the value of the producing firm solves

$$
\rho J\left(w_{k}\right)=A_{k}-w_{k} /(1-\kappa)-\lambda_{k}\left[J\left(w_{k}\right)-J_{0 k}\right] .
$$

The difference $A_{k}-w_{k} /(1-\kappa)$ on the right hand side of this Bellman equation shows the instantaneous profit. The remaining term illustrates the expected capital loss of the firm due to exogenous job destruction.

Vacant firms do not produce, incurring instead the flow cost $\gamma_{k}$ of advertising the vacancy. Vacancies meet unemployed workers at rate $\bar{\mu}_{k} / \theta_{k}$, where $\bar{\mu}_{k}$ is the job finding rate of skill group $k$. Since $\phi_{k}(s)$, and hence $\mu_{k}(s, \chi)$, are time-dependent for the reasons described above, the distribution of unemployment duration is no longer exponential, as in the textbook model. The expected entry rate is given by

$$
\bar{\mu}_{k}=\pi^{\chi} \int_{0}^{\infty} \mu_{k}(s, 1) f_{k}(s, 1) d s+\left(1-\pi^{\chi}\right) \int_{0}^{\infty} \mu_{k}(s, 0) f_{k}(s, 0) d s,
$$

where $f_{k}(s, \chi)$ is the equilibrium probability density of unemployment duration of the workers with skill level $k$ and search productivity $\chi$. As known, this density can be completely 
described by the hazard rate $\mu_{k}(s, \chi)$, whereas the expression for the latter is given in (2). We assume free entry into any of $k$ markets which amounts to value of the vacant job being equal to zero, $J_{0 k}=0$. This reduces the Bellman equation for the value of the vacant firm to $\gamma_{k}=\theta_{k}^{-1} \bar{\mu}_{k} J\left(w_{k}\right)$ where $\gamma_{k}$ denotes the period vacancy cost and the right-hand side captures the expected value of future production.

\section{- Government}

The government finances unemployment benefits through labour tax revenues. Let $N_{k}$ denote the fixed size of the labour force of skill $k$. Let $L_{k}$ denote the endogenous size of employment of this skill, such that $U_{k} \equiv N_{k}-L_{k}$ is the size of unemployment. Then, the measures of UI and UA recipients are given by $U_{k}^{U I}=\left(N_{k}-L_{k}\right)\left[\pi^{\chi} \int_{0}^{\bar{s}} f_{k}(s, 1) d s+\right.$ $\left.\left(1-\pi^{\chi}\right) \int_{0}^{\bar{s}} f_{k}(s, 0) d s\right]$ and $U_{k}^{U A}=\left(N_{k}-L_{k}\right)\left[\pi^{\chi} \int_{\bar{s}}^{\infty} f_{k}(s, 1) d s+\left(1-\pi^{\chi}\right) \int_{\bar{s}}^{\infty} f_{k}(s, 0) d s\right]$, respectively.

The measure $U_{k}^{U I}$ receives $b_{U I}$ and the measure $U_{k}^{U A}$ receives $b_{U A}$. These are paid by the labour tax levied on the gross wage $w_{k} /(1-\kappa)$ of the employed workforce $L_{k}$. Consequently, the budget of the government is given by $\Sigma_{k=1}^{K} b_{U I} U_{k}^{U I}+\sum_{k=1}^{K} b_{U A} U_{k}^{U A}=\Sigma_{k=1}^{K} \kappa \frac{w_{k}}{1-\kappa} L_{k}$. The government chooses the tax rate $\kappa$ such that this budget is balanced at any time.

- Equilibrium

Equilibrium is characterized by the set $\left\{w_{k}, u_{k}, \theta_{k}\right\}_{k=1}^{K}$ of skill-specific wages $\left(w_{k}\right)$, unemployment rates $\left(u_{k}\right)$ and tightness parameters $\left(\theta_{k}\right)$ which satisfy the optimal solutions of workers' and firms' problems such that the government budget is balanced.

Wages are set according to collective bargaining, where we explicitly account for the fact that UI and UA benefits (prior to the reform) are proportional to previous net wage. The corresponding wage equation reads

$$
\begin{aligned}
& (1-\beta) v\left(w_{k}\right)+\beta m_{w_{k}}(.) w_{k} \\
& =(1-\beta) v\left(b_{U I, k}, \phi_{k}(0)\right)+\beta(1-\kappa) m_{w_{k}}(.)\left[A_{k}+\gamma_{k} \theta_{k} \frac{\mu_{k}\left(\phi_{k}(0) \theta_{k}, p_{0}\right)}{\bar{\mu}_{k}}\right],
\end{aligned}
$$

where

$$
m_{w_{k}}\left(w_{k}, b_{U I}, \phi_{k}(0)\right) \equiv v_{w}\left(w_{k}\right)+\frac{\lambda_{k}}{\rho+\mu_{k}\left(\phi_{k}(0) \theta_{k}, p_{0}\right)} v_{w}\left(b_{U I, k}, \phi_{k}(0)\right)
$$

This equation is more general than textbook versions due to risk-aversion, benefit levels proportional to the wage and the non-stationarity of unemployment benefits. If we had riskneutrality and wage-independent unemployment benefits, the marginal effect of the wage on utility in (10) would be unity. The left-hand side of (9) would then equal $w$, the net wage. In our more general setup, an increase in the wage increases utility in (10) by the slope at the current wage $w_{k}$ plus the marginal effect of a higher wage on future utility when the individual is unemployed again and income is given by the benefit $b_{U I, k}$. This future utility also depends on effort $\phi_{k}(0)$ and affects current utility in expectation, where $\lambda_{k}$ is the rate with which the individual loses the current job. Future utility is expressed in its present value where discounting takes place at the time preference rate plus the job arrival rate $\mu_{k}\left(\phi_{k}(0) \theta_{k}, p_{0}\right)$ with which an individual would then find a job again. 
The right hand side of (9) shows the contribution of utility from benefits when just having lost the job and the tax-rate weighted effect of the production side. As in the standard setup, higher benefits yield higher wages, as does higher productivity. The effect of more vacancies per unemployed worker, i.e. of higher $\theta_{k}$, is weighted by the arrival rate once unemployed divided by the average arrival rate. This latter generalization is due to the non-stationary nature of benefit payments.

An essential insight of our model, as well as its main contribution to the theoretical literature, is the derivation of the equilibrium unemployment rate for a non-stationary benefit system (1). This nonstationarity implies a semi-Markov setup, where instantaneous transition probabilities from unemployment to employment are no longer independent of unemployment duration. The equilibrium unemployment rate in such case is found via the solution to a system of Volterra integral equations.

The expression for the long-term unemployment rate following from this setup reads

$$
u_{k}=\frac{p_{e u}^{k}}{p_{e u}^{k}+\int_{0}^{\infty} p_{u e}^{k}(s) d F^{k}(s)},
$$

where $p_{e u}^{k}$ is the steady-state probability of being unemployed conditional on having had a job. Similarly, $p_{e u}^{k}(s)$ is the probability that an originally employed individual is unemployed in $s$. The distribution of unemployment spells in skill group $k$ is denoted by $F^{k}(s)$. Interestingly (and necessarily), the standard expression $u_{k}=\lambda^{k} /\left(\lambda^{k}+\mu^{k}\right)$ is a special case of our setup. When all job-finding rates are constant, given by $\mu^{k}$ for any $k$, the corresponding probabilities become $p_{e u}^{k}=\lambda^{k} /\left(\lambda^{k}+\mu^{k}\right)$ and $p_{u e}^{k}=\mu^{k} /\left(\lambda^{k}+\mu^{k}\right)$.

\subsection{The effect of more productive PEAs}

From our specification of the productivity parameter $\psi(s)$ of the public employment agency in (2) it is clear that one should talk about productivities of a PEA once it comes to duration of unemployment. Indeed, the Hartz III reform affected various "units" of the PEA in Germany in a heterogenous way. One facet of this heterogeneity was the provision of specialized advice to long-term unemployed, as mentioned in Section 2.2.2. Estimates from the literature (Klinger and Rothe, 2012), which we are going to employ for our analysis below, have actually shown that the reform had quite distinct effects on hirings of short- and long-term unemployed workers.

In order to facilitate our understanding of the quantitative effects of more productive PEAs, we will first look at the theoretical prediction our model makes. We are interested in the effect of increased productivity of a PEA on the total number of hirings and on the aggregate unemployment rate. The results for identical productivity increases of PEA are as expected: We start with a spell-independent productivity of a PEA, i.e. with $\psi(s)=\psi$, and take a steady state that reflects the situation in Germany before any reform as starting point. ${ }^{6}$ Starting from there, a rise of $\psi$ by $5 \%, 10 \%$ and $20 \%$ reduces the unemployment rate by $7.0 \%, 13 \%$ and $22 \% .^{7}$ More generally, within a reasonable scope of increase of $\psi$ there is

\footnotetext{
${ }^{6}$ This means we let $b_{U I}$ and $b_{U A}$ reflect the values from the period before the Hartz reforms and normalize the productivity of the PEA to one, $\psi=1$.

${ }^{7}$ The matlab code for the numerical solution plus documentation are available at http://www.empirical.economics.uni-mainz.de/115.php and at www.waelde.com/pub.
} 
a monotone decreasing relationship between the productivity of the PEA on the one hand and the aggregate unemployment rate on the other.

This picture changes dramatically, however, if we allow for heterogeneous increases of the productivity of a PEA for short- and long-term unemployed. Our model shows that an increase in productivity of a PEA can sometimes lead to an increase in the unemployment rate. To illustrate the mechanism most clearly, let $\psi(s)=\psi^{U I}$ when $0 \leq s \leq \bar{s}$ and $\psi(s)=\psi^{U A}$ when $s>\bar{s}$. Furthermore, assume for the time being that the reform of a PEA had no effect on productivity of the agency for short-term unemployed workers, i.e. $\psi^{U I}=1$. We ask what is the effect of a change in $\psi^{U A}$ on total hirings and the aggregate unemployment rate. The answer is plotted in fig. 2 for $\psi^{U A}$ ranging between 0.8 and 1.4.
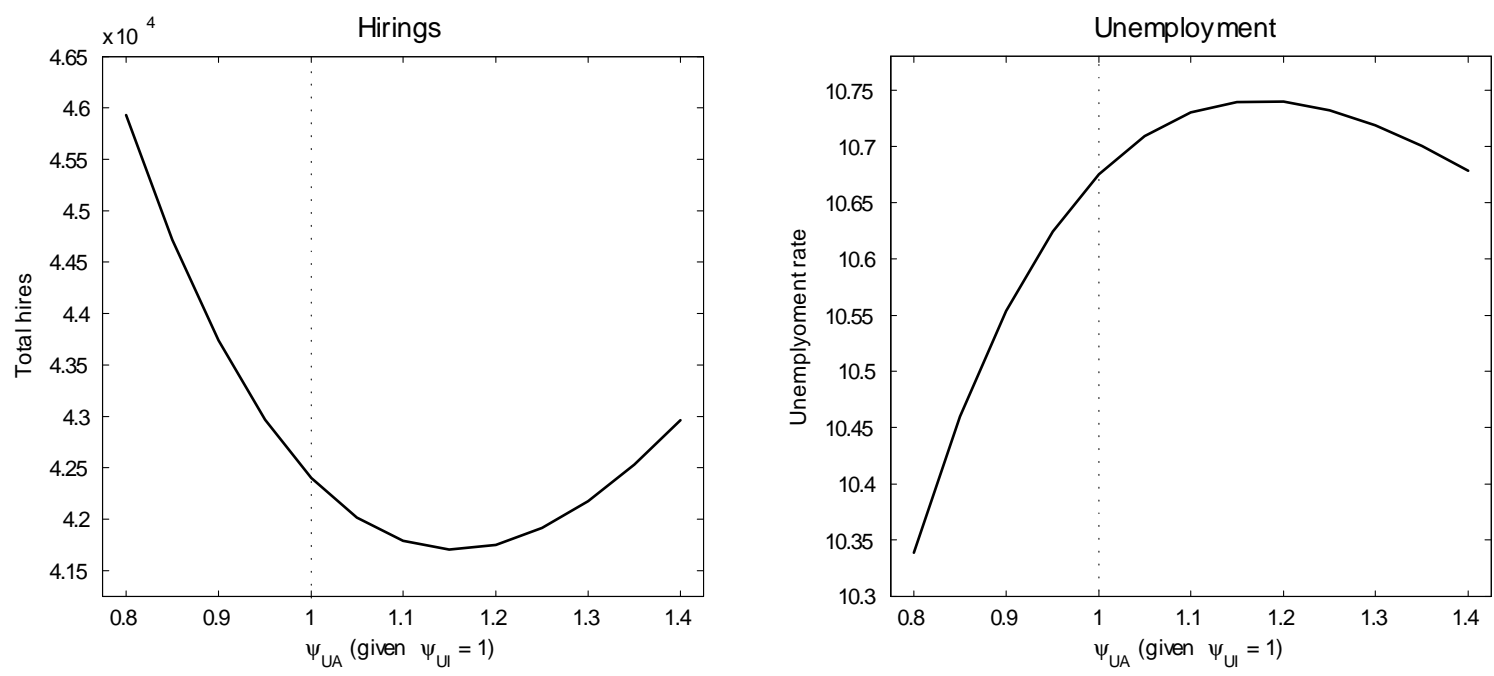

Figure 2 Changes in total hirings and the unemployment rate under differing impact of PEA productivity

The left panel of this figure displays the aggregate number of matches $\Sigma_{k=1}^{K} \bar{\mu}_{k} U_{k}$, where $\bar{\mu}_{k}$ is given by (8) and $U_{k}$ denotes the number of unemployed workers in skill group $k$. The right panel plots the aggregate equilibrium unemployment rate with aggregation across all skills, i.e. $\Sigma_{k=1}^{K} \frac{N_{k}}{N} u_{k}$ where $u_{k}$ is from (11). This figure clearly shows the "immiserizing growth" effect: When productivity $\psi^{U A}$ of public employment agency rises for long-term unemployed workers, holding productivity $\psi^{U I}$ of short-term unemployed fixed, hirings initially go down and unemployment increases. When productivity $\psi^{U A}$ rises further, hirings rise again and unemployment falls.

This paradox emerges as there are two forces at work: A direct productivity effect for the long-term unemployed workers and an indirect disincentive effect for the short-term unemployed workers. The direct productivity effect per se is beneficial, i.e. higher productivity increases hirings and reduces the unemployment rate. The disincentive effect results from the anticipation by short-term unemployed workers that their exit rate will become higher once they are long-term unemployed. As a consequence, they reduce their search effort and the exit rate of short-term unemployed workers goes down. Total hirings tend to go down as well 
and unemployment rises. As either of the two effects can dominate, the non-monotonicity arises.

To back our intuition on the indirect incentive effect, consider the total number of matches $M$ which in our model amounts to

$$
M=\sum_{k=1}^{K} M_{k}=\sum_{k=1}^{K} \bar{\mu}_{k} U_{k}=\sum_{k=1}^{K}\left(\bar{\mu}_{k}^{U I}+\bar{\mu}_{k}^{U A}\right) U_{k}
$$

where $M_{k}$ is the number of matches in group $k$ and

$$
\begin{aligned}
& \bar{\mu}_{k}^{U I} \equiv \pi^{\chi} \int_{0}^{\bar{s}} \mu_{k}(s, 1) f_{k}(s, 1) d s+\left(1-\pi^{\chi}\right) \int_{0}^{\bar{s}} \mu_{k}(s, 0) f_{k}(s, 0) d s \\
& \bar{\mu}_{k}^{U A} \equiv \pi^{\chi} \int_{\bar{s}}^{\infty} \mu_{k}(s, 1) f_{k}(s, 1) d s+\left(1-\pi^{\chi}\right) \int_{\bar{s}}^{\infty} \mu_{k}(s, 0) f_{k}(s, 0) d s
\end{aligned}
$$

are the interval-specific average exit rates following directly from (8). ${ }^{8}$ The right-hand side of (12) implies that matches change when (i) the number of unemployed changes and (ii) the interval-specific average exit rates change. The impact of changing $\psi^{U A}$ on the number of unemployed, keeping $\psi^{U I}$ fixed, has been already illustrated in fig. 2. Should the differences in the productivity of a PEA for long-term unemployed influence search incentives of shortterm unemployed as conjectured above, it has to be that under $\psi^{U I}=1$ all $\psi^{U A}<1$ would lead to a higher average short-term effort, and hence exit rate. This will simply reflect the anticipation of being shifted to a low-productive PEA unit after the expiration of entitlement. Similarly, for all $\psi^{U A}>1$ anticipation of dealing with a more efficient PEA unit would slow down search activity in the short term, making the average exit rate lower than in the case of no differences in productivity of matching technology. This is exactly what we can see in the next figure.

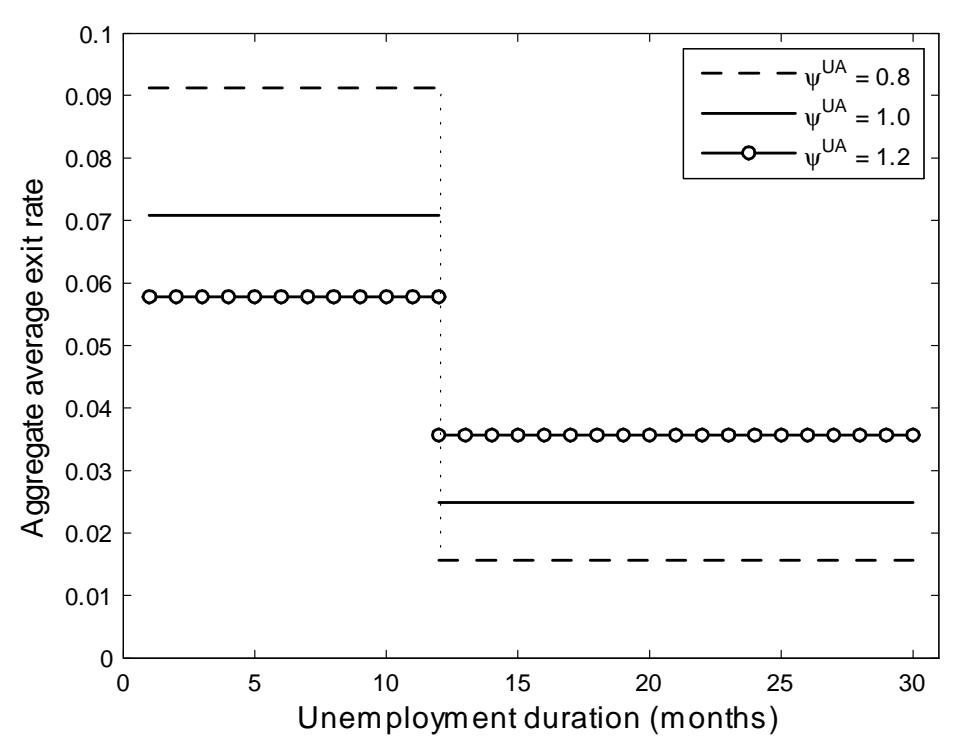

Figure 3 Understanding the paradox: Changes in average exit rates

\footnotetext{
${ }^{8}$ Note that $\bar{\mu}_{k}^{U I}$ is not the average exit rate of short-term unemployed. The same applies to $\bar{\mu}_{k}^{U A}$.
} 
Fixing $\psi^{U I}=1$, fig. 3 depicts the aggregate interval-specific average exit rates, where aggregation is with respect to skills. It considers three different cases: $\psi^{U A}=\{0,8,1.0,1.2\}$. The plain solid line is the agency that is equally effective for short- and long-term unemployed $\left(\psi^{U I}=\psi^{U A}=1\right)$. This is the benchmark. Once the agency becomes relatively less effective in the long term $\left(\psi^{U A}=0.8\right.$; dashed line) the exit rate rises for UI recipients and falls for UA recipients. The converse is true for the agency that is relatively more effective in the long term $\left(\psi^{U A}=1.2\right.$; solid line with circles). The exit rate for long-term unemployed workers goes up, but the exit rate for short-term unemployed workers falls.

Summing up the discussion, how well the focus of a reform on long-term unemployed workers is tuned with changes in the productivity of a PEA for short-term unemployed is always an empirical question. It cannot be taken for granted, however, that any change of a productivity of an agency will lead to a reduction of the unemployment rate.

\subsection{Assessment strategy}

With the help of the model just described we simulate the contribution of the reform packages of interest to the reduction of the unemployment rate from the beginning of 2005 up to the onset of the Great Recession in 2008. ${ }^{9}$ We use the existing reduced-form estimates to pin down the impact of the reform of the PEA (Hartz III). After that we determine the role of reduced benefit generosity (Hartz IV) via simulating the transition to the ALG II system with fixed UA benefits and the reduction of entitlement to UI benefits as defined by the legislation. This simulation is done both in the actual environment with Hartz III having taken place prior to Hartz IV and in the counterfactual environment of the absence of Hartz III. Comparison of the actual and counterfactual results allows studying the role of the reform of the PEA for the success (or absence thereof) of the benefit reform.

\section{- The impact of Hartz III}

We model the effect of Hartz III by allowing it to influence the productivity of the matching process $\psi(s)$ in different phases of an unemployment spell in a distinct way. We pin down $\psi(s)$ by requiring that the number of matches in our model after the reform of the PEA is the same as the number of matches before the reform times the estimated increase in the number of matches due to the reform. To be precise, consider the case of a homogeneous $\psi(s)=\psi$ where we require

$$
\sum_{k=1}^{K} \bar{\mu}_{k} U_{k}=\delta \sum_{k=1}^{K} \bar{\mu}_{k}^{*} U_{k}^{*}
$$

The estimated increase of the number of matches due to Hartz III obtained in the reducedform estimation is $\delta$. The number of matches in our model before any reform, i.e. where $\psi(s)=1$, is $\sum_{k=1}^{K} \bar{\mu}_{k}^{*} U_{k}^{*}$ on the right-hand side. The number of matches required after the reform is $\delta \sum_{k=1}^{K} \bar{\mu}_{k}^{*} U_{k}^{*}$. We obtain this number of matches as the equilibrium outcome of our structural model by adjusting $\psi$ such that this equality holds. This equality can hold as the productivity parameter $\psi$ appears on the left hand side of (14) because the individual job

\footnotetext{
${ }^{9}$ As argued by Krause and Uhlig (2012), most of the transition to the new steady state after the benefit reform took no longer than three years. Year 2009 also marks the end of the transition schedule of the directive and operative capacities of PEA under Hartz III (see Weise, 2011).
} 
arrival rate (2) is a function of $\psi$ and the individual job arrival rate determines the average arrival rate $\bar{\mu}_{k}$ from (8). ${ }^{10}$ As the left-hand side monotonically increases in $\psi$, this equation allows us to determine a unique productivity increase of the PEA due to the Hartz III reform. Although all our final statements will be made on the basis of differing impacts of the reform of the PEA on short- and long-term unemployed, it will turn out to be quite instructive to consider first the more restrictive specification of the homogeneous impact with single $\psi$ (see section 4.1.2 for detailed discussion).

When the impact of the reform is heterogeneous, we end up with two equations,

$$
\begin{aligned}
& \sum_{k=1}^{K} \bar{\mu}_{k} U_{k}^{\text {short }}=\delta^{U I} \sum_{k=1}^{K} \bar{\mu}_{k}^{*} U_{k}^{* \text { short }}, \\
& \sum_{k=1}^{K} \bar{\mu}_{k} U_{k}^{\text {long }}=\delta^{U A} \sum_{k=1}^{K} \bar{\mu}_{k}^{*} U_{k}^{* \text { long }} .
\end{aligned}
$$

In our structural model, the expected number of matches per unit of time in a group $k$ before the reform is given by $\bar{\mu}_{k}^{*} U_{k}^{* \text { short }}$ for the short-term unemployed and $\bar{\mu}_{k}^{*} U_{k}^{* \text { long }}$ for the longterm unemployed workers. In both cases, $\bar{\mu}_{k}^{*}$ is the expression from (8) for $\psi^{U I}=\psi^{U A}=1$ and both $U_{k}^{* \text { short }}$ and $U_{k}^{* \text { long }}$ are as defined on p. 12. Reduced-form estimates provide us with information on percentage changes of total matches induced by the reform separately for short- and long-term unemployed workers. Let us denote these percentage changes of total matches of short- and long-term unemployed by $\delta^{U I}$ and $\delta^{U A}$, respectively. With this, the number of total matches after the reform will be given by $\delta^{U I} \sum_{k=1}^{K} \bar{\mu}_{k}^{*} U_{k}^{* \text { short }}$ for shortand $\delta^{U A} \sum_{k=1}^{K} \bar{\mu}_{k}^{*} U_{k}^{* \text { long }}$ for long-term unemployed workers. These are the expressions on the right-hand sides of (15a, b).

As a result of the reform, the productivity of the PEA for short-term unemployed has increased by $\psi^{U I}>1$ and the productivity of the PEA for long-term unemployed has increased by $\psi^{U A}>1$. This gives rise to a new equilibrium with the average exit rate $\bar{\mu}_{k}$ and the measures of short- and long-term unemployment workers of $U_{k}^{\text {short }}$ and $U_{k}^{\text {long }}$. Again, as the productivity parameters enter the average exit rate $\bar{\mu}_{k}$, this constitutes a system of two equations with two unknowns.

Given the heterogeneous productivity paradox discussed earlier after fig. 2, however, a fixed number of matches in the new equilibrium in this system will generally imply two solutions for the unknown structural-form parameters of PEA productivities $\psi^{U I}$ and $\psi^{U A}$. To discriminate between these solutions, the identifying assumption is that $\psi^{U I}$ and $\psi^{U A}$ must always increase as a result of the reform (i.e. $\psi^{U I}>1$ and $\psi^{U A}>1$ in the new equilibrium). With this highly plausible restriction, we will be able to uniquely determine $\psi^{U I}$ and $\psi^{U A}$ in our application below.

One might be tempted now to argue that using the very same technique as above one can estimate the influence of Hartz I and II left out in the present paper. Indeed, estimates of the increase in matches after Hartz I and II are available from the reduced-form literature just like they are available for Hartz III. It therefore seems natural to mirror this increase in matches by our structural model as well. While there are several ways of how this can be achieved (e.g. increase the productivity of workers, reduce the entry costs of firms, etc.), heterogeneity of policy measures associated with Hartz I and II commands that a whole set of

\footnotetext{
${ }^{10}$ As Klinger and Rothe (2012) do not provide skill-specific values of $\delta$, we need to assume that $\delta$ is the same across all skills.
} 
structural parameters that relate to multitude of policies should be changed simultaneously. Modelling requirements to do so go far beyond the objective of this paper.

Even if such theoretical modelling is undertaken, it is far from clear whether all of these parameters can be uniquely identified from a reduced form. It is clear, however, that the increase in matches after Hartz I and II must not be replicated by an increase in the productivity $\psi$ of the matching process alone. Hartz I and II include many measures which affect individual behaviour in diverse ways (like e.g. sanctions or subsidies to self-employment start-ups), such that the channel is not only the matching productivity. Conclusions that would be drawn from an increase of $\psi$ exclusively will consequently be misleading.

- The impact of Hartz IV

To simulate the effect of Hartz IV, we look at each of the $K$ heterogeneous groups simultaneously and in equilibrium. We consider the observed distribution of UA payments immediately before the reform and the observed distribution of ALG II payments immediately after the reform. The difference in the mean values of these distributions marks the group-specific change in benefit level due to the introduction of the ALG II system. In this way we naturally get the winners and losers of the reform, documented otherwise in existing empirical studies. ${ }^{11}$

We deal with the reduction of entitlement length in a similar way. Within each of the $K$ heterogeneous groups, we consider two different distributions of the entitlement length. The first one is the actual distribution immediately before the reform. The second one is the counterfactual distribution computed on the same sample according to post-reform rules. The difference in the means of these two distributions marks the group-specific reduction of the entitlement imposed by the reform.

We simulate the regime switch from UA to ALG II benefits and the reduction of the entitlement to UI simultaneously.

\section{Efficient agency or more benefit cuts?}

\subsection{Impact on equilibrium unemployment}

\subsubsection{Specification}

We now present a detailed discussion of equilibrium effects of the two reforms in question. We undertake a comparative dynamics analysis to determine the contribution of the reform of the PEA, as well as that of the benefit system, to the reduction of the unemployment rate between 2005 and 2008. This analysis is performed under two different specifications. The first specification restricts the impact of the reform of the PEA to be the same for short- and long-term unemployed, i.e. $\delta^{U I}=\delta^{U I} \equiv \delta$, implying a unique $\psi$. The second specification lifts this restriction and allows for differing impacts, i.e. $\delta^{U I} \neq \delta^{U A}$, implying $\psi^{U I} \neq \psi^{U A}$.

\footnotetext{
${ }^{11}$ We find that about $1 / 4$ of all unemployed win from the new benefit scheme, obtaining higher payments than what they would have got without the reform. This aligns e.g. with the result of Goebel and Richter (2007) who find that about $1 / 3$ of all unemployed improve their position after the introduction of ALG II, as well as with the similar earlier result of Blos and Rudolph (2005).
} 
We take the reduced-form estimates of the $\delta$ s from Klinger and Rothe (2012). When they constrain their specification to a single $\delta$, they estimate an increase in matches by $3.5 \%$ (their table 1, column 2). When they allow for heterogeneous $\delta$ s (their table 3 , column 4 ), they find that matches of short-term unemployed have increased by $2.1 \%$ and matches of long-term unemployed have increased by $6.1 \%$. All other estimates are the structural estimates taken from Launov and Wälde (2013).

Comparative dynamics analysis is conducted by means of the out-of-sample structural prediction, for which we collect individual data from the last three years before the introduction of the reform (years 2001 to 2003) and take the labour market tightness data of 2005. ${ }^{12}$ Remarkably, our model has very good predictive properties. The predicted aggregate unemployment rate in the pre-reform steady state amounts to $10.68 \%$, which falls short of the actually observed unemployment rate of $11.71 \%$ by just 1.03 percentage points.

To asses whether this prediction error is of any importance we perform a robustness check via exact calibration. When setting up the calibration, instead of taking the actual data on the labour market tightness, we choose the tightness ourselves so as to match the observed aggregate unemployment rate of $11.71 \%$ exactly. It turns out that our comparative dynamics analysis is absolutely robust to the choice of the assessment method.

The results of the structural prediction are reported in Section 4.1.2. The results of the robustness check via exact calibration are shown in the Appendix (see tab. A.3). Furthermore, tab. A.1 of the Appendix provides complete description of the pre-reform steady states used for structural prediction and exact calibration.

\subsubsection{The reform and the fall of unemployment}

Table 1 reports the simulated effect of the reform of the PEA, as well as that of the benefit reform, measured in percentage points reduction of the aggregate unemployment rate. The first block of this table shows the results from the specification in which the reform of the PEA has increased the productivity of the agency for short- and long-term unemployed workers by the same amount. The second block of tab. 1 does the same for the increases in the productivities of the PEA that differ across short- and long-term unemployed workers.

Consider first the simulation with an identical increase in the productivity of the PEA for short- and long-term unemployed. Under this specification the estimated $3.5 \%$ rise in the total number of matches from Klinger and Rothe (2012) is reflected in the reduction of the equilibrium unemployment rate by 1.98 percentage points (block 1, line 1). The corresponding increase $\psi$ in the productivity of the agency in the structural model amounts to 1.16. The productivity of the PEA has increased by $16 \%$ as a result of the reform. This explains almost exactly a half of the observed decline of the unemployment rate between 2005 and 2008, implying that the reform of the PEA under arrangements of Hartz III turns out to be an extremely powerful tool for reducing unemployment. This is the first remarkable result of our analysis.

Next, keeping the assumption of the identical impact of the reform of the PEA, we simulate the reform of benefits. We do this sequentially, i.e. after Hartz III, and independently,

\footnotetext{
${ }^{12}$ It turns out that the distribution of individual data is fairly stable over time. The labour market tightness, in contrast, fluctuates considerably. As we try to describe the evolution of the unemployment rate between 2005 and 2008, we pick the tightness of 2005 as a starting point.
} 
i.e. in absence of Hartz III. We find that in both cases the contribution of the reduced benefit generosity is anything but sizeable. Once the benefit reform is conducted in the counterfactual situation of the absence of the reform of the PEA, it accounts for only 0.08 percentage point decline of the equilibrium unemployment rate (block 1, line 2). This explains merely $2.05 \%$ of the observed drop in unemployment. Once the benefit reform is conducted after the reform of the PEA, which is the actual sequence of implementation, the total impact of both packages of the Hartz reform amounts to 2.08 percentage point reduction of the unemployment rate (block 1, line 3). This implies that conditional on the reform of the PEA having taken place, the reform of benefits can explain a decline of the equilibrium unemployment rate of just 0.10 percentage points (block 1 , line 4 ). This amounts to explaining only $2.56 \%$ of the observed drop in unemployment.

\begin{tabular}{|c|c|c|c|c|c|}
\hline & & \multicolumn{2}{|c|}{ Identical impact } & \multicolumn{2}{|c|}{ Differing impact } \\
\hline & & $\begin{array}{c}\text { absolute } \\
\text { reduction (ppt) }\end{array}$ & $\begin{array}{c}\text { explained } \\
\text { reduction (\%) }\end{array}$ & $\begin{array}{c}\text { absolute } \\
\text { reduction (ppt) }\end{array}$ & $\begin{array}{c}\text { explained } \\
\text { reduction (\%) }\end{array}$ \\
\hline (1) & Hartz III & 1.98 & $50.64 \%$ & 1.32 & $33.76 \%$ \\
\hline (2) & Hartz IV & 0.08 & $2.05 \%$ & 0.08 & $2.05 \%$ \\
\hline (3) & Hartz III \& IV & 2.08 & $52.94 \%$ & 1.62 & $41.43 \%$ \\
\hline (4) & $\begin{array}{l}\text { Hartz IV given } \\
\text { Hartz III }^{\mathrm{a})}\end{array}$ & 0.10 & $2.56 \%$ & 0.30 & $7.67 \%$ \\
\hline (5) & $\begin{array}{l}\text { Interaction of } \\
\text { Hartz III and } \\
\text { Hartz IV }\end{array}$ & 0.02 & $0.51 \%$ & 0.22 & $5.63 \%$ \\
\hline
\end{tabular}

a) Line (3) minus line (1) b) Line (4) minus line (2)

Table 1 Simulated reduction of the unemployment rate

The above findings lead us to two interesting conclusions. First and foremost the benefit reform can hardly be called important once it comes to the German success of curbing unemployment in mid 2000s. Second, it seems that the success of the benefit reform, which was targeting long-term unemployed workers, does not depend much on the prior reform of the PEA. The interaction effect of both reforms can be computed as the difference between the impact of Hartz IV given the reform of the PEA and Hartz IV without this reform (block 1, line 5). Sticking to the case of identical impacts, the interaction effect amounts to negligible 0.02 percentage points.

The picture changes in a very interesting way, however, if we consider a differing impact of Hartz III on the productivity of the agency for short- and long-term unemployed. For the estimated rise of $2.1 \%$ in total matches of short-term unemployed and $6.1 \%$ in total matches 
of long-term unemployed workers, we find productivities of $\psi^{U I}=1.15$ and. $\psi^{U A}=1.65$. The agency has therefore become $15 \%$ more productive for short-term unemployed and $65 \%$ more productive for long-term unemployed. As a consequence, the PEA reform has reduced the equilibrium unemployment rate by 1.32 percentage points (block 2, line 1). ${ }^{13}$ This explains just slightly above $1 / 3$ of the observed post-reform unemployment decline, which is a substantial number. Thus, our first remarkable result on the important role of a PEA in harnessing German unemployment in mid 2000s persists.

The obvious difference between the explained unemployment decline in the initial specification with an identical productivity increase of the PEA (50.64\%) and the extended specification with productivity increase of the PEA heterogeneous across short- and longterm unemployed $(33.76 \%)$ is due to the mechanism explained in Section 3.2. As the design of the reform has favoured long-term unemployed workers more than short term ones, shortterm unemployed workers have become subject to two opposing influences. The first one is the positive effect of the PEA productivity increase by $15 \%$, which pushes the exit rate up and thus reduces unemployment. The second one is the negative incentive effect through the even higher productivity increase of the agency for long-term unemployed. The closer shortterm unemployed individuals are to expiration of their entitlement to UI, the closer they are to being shifted to another "unit" of the PEA that is about five times more productive in matching workers with vacancies than their current one. This anticipation reduces the current search effort, which eventually leads to lower exit rate and higher unemployment. As we see from tab. 1, the positive productivity effect has dominated the negative incentive effect, so unemployment was still falling by over $1 / 3$ as a result of the reform of the PEA.

The second remarkable result of our analysis is on the role of the PEA reform for the success of the benefit reform. As we have already seen, once the reform of a PEA equally affects short- and long-term unemployed, the benefit reform brings nearly identical results no matter if conducted after the reform of the agency or in absence of this reform. Nothing of this kind obtains anymore once heterogeneity in productivity of the agency with respect to short- and long-term unemployed is allowed for. The second block of tab. 1 shows that reduced generosity of unemployment benefits, implemented after the reform of the PEA, accounts now for 0.30 percentage point reduction of the equilibrium unemployment rate (block 2, line 4). This explains $7.67 \%$ of the observed unemployment decline. Since the result for the benefit reform in the counterfactual absence of the reform of the PEA does not change (block 2, line 2), a PEA reform that favours long-term unemployed workers delivers in a non-negligible interaction effect between Hartz III and Hartz IV. This interaction effect explains 0.22 percentage points (equivalently, 5.63\%) of the decline of the equilibrium unemployment rate (block 2, line 5). This is nearly three times stronger than the effect of the benefit reform conducted in the counterfactual environment of an absence of the reform of the PEA. Although the interaction effect is still quite modest in terms of numbers, this result is remarkable for the fact that heterogeneity in the reform of the PEA may reduce the effectiveness of the reform of the PEA itself, but at the same time may improve the strength of the other reforms that follow.

\footnotetext{
${ }^{13}$ As evident from fig. 2, there exist two solutions for productivity parameters of the agency. We also find $\psi^{U I}=0.92$ and $\psi^{U A}=0.75$. Given our identifying assumption discussed earlier we impose that $\psi^{U I}>1$ and $\psi^{U A}>1$. Note that with both productivity values below one, the PEA reform would have caused the unemployment rate to increase from $10.68 \%$ to $12.46 \%$.
} 
Figure 4 visualizes the impacts of both packages. For each specification it plots the shares of observed unemployment decline explained by the reform of the PEA and the benefit reform, the latter including the interaction effect with the preceding reform of the PEA. It clearly shows the disincentive effect of the heterogeneous change in productivity of the agency (comparison of dark grey bars) and the effect of benefit reform amplified by interaction with the reform of the PEA (comparison of light grey bars). The explained shares of the second specification in the middle constitute our final results for the effect of both Hartz packages on the reduction of the observed unemployment rate. The reform of the PEA (accounting for $34 \%$ of the observed decline in unemployment) was 4 to 5 times more effective in reducing the unemployment rate than the reform of benefit payments $(7 \%)$.

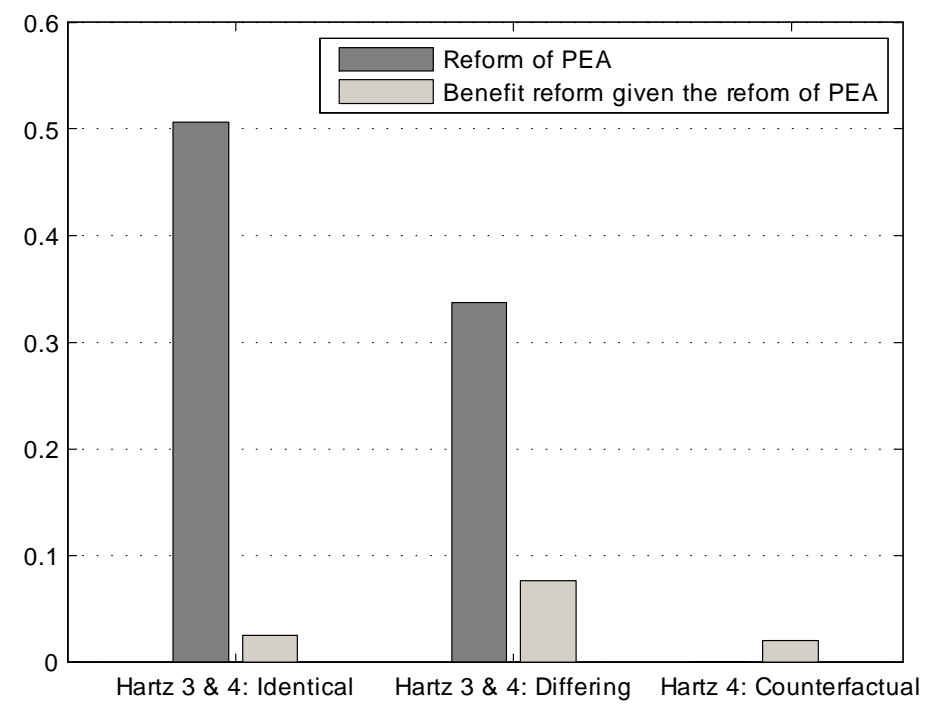

Figure 4 Share of the observed unemployment decline explained by the reform

Ultimately, another intriguing question would have been: What would have happened if the benefit reform was implemented prior to the reform of the PEA? In other words, what would have been the effect of Hartz III if the order of implementation of Hartz III and Hartz IV was reversed? While theoretically our structural model allows computing such an effect as well, to do so we would require the counterfactual reduced-form estimate of the increase in the number of matches induced by the reform of the agency. This estimate is no longer the same as the available estimates of Klinger and Rothe (2012), because the available estimates rely on the actual order of implementation. Since for the counterfactual order of implementation no suitable reduced-form results exist to this date, our present analysis of the reform of the PEA is confined just to the actual sequence of implementation.

\subsection{Reform implications}

What do we learn from this analysis for future reforms? There is a discussion in Germany on a second Hartz-type reform and, much more importantly, there is a discussion at the 
European level on how to fight the highest unemployment rates in the Euro area ever since the Euro was introduced in 2002. ${ }^{14}$ How can policy measures be informed by our findings?

In some trivial sense, anything that increases the outflows from and reduces the inflows into unemployment is desirable. It is less trivial to suggest measures that actually increase outflows and reduce inflows. The most challenging task consists in quantifying the effects of the suggested measures.

Our analysis makes a strong case, surprising even to us, for an increased effectiveness of PEAs. What speaks in favour of more effective PEAs as opposed to a cut of benefits for long-term unemployed? First, the strong direct effect on the increase of outflows from unemployment. A more efficient PEA does not only increase outflow of long-term unemployed workers - once appropriately tuned, it benefits all unemployed workers. Second, the neutrality of a such a policy measure with respect to distributional considerations. While a cut of benefits for long-term (or all) unemployed workers should increase outflows (if only modestly as we have found), it increases income inequalities and poverty.

Is there a direct recommendation for "any" country with high unemployment? We would say no when it comes to detailed reform measures. Our findings very strongly suggest, however, that any country should first study potentials in making its PEAs more effective before thinking about reducing unemployment benefits. From reading descriptions of the reform of the German PEA, the best conclusions on which components were the most important ones are the following. (i) There is one contact person for all aspects related to unemployment for one unemployed worker. (ii) Short questions can be resolved via a call-center. (iii) More time-intensive consultations are by appointment only, reducing considerably waiting times in the agency. ${ }^{15}$ (iv) the number of unemployed managed by a caseworker was reduced to the benchmark of at most 150 (of which at most 75 are under age of 25 years) and (v) priority was given to workers above the age of $50 .{ }^{16}$ The Annual Report of the Federal Employment Agency (Bundesagentur für Arbeit, 2013, p.43) provides empirical confirmation that the quantitative benchmarks have actually been met (but only in 2012).

The implication of homogeneous vs heterogeneous reform implications should also not be left aside. As our estimates indicate, the PEA reform would have had even a higher effect on the reduction of unemployment if the PEA as a whole had benefited equally. In the case of an identical impact in table 1, unemployment would have decreased by 1.98 percentage points as opposed to "only" 1.32 percentage points in the current case. A homogenous reform would have accounted for more than $50 \%$ of the reduction of the observed unemployment rate.

\footnotetext{
${ }^{14}$ See e.g. the new release 50/2013 of 2 April 2013 by Eurostat.

${ }^{15}$ An impressive description is by Weise (2011), the current head of the German PEA. It strongly makes the case that the reorganization of all work-flows turned an administrative bureaucracy (that became fraudualent in parts of its activities) into a customer (i.e. employee and employer) oriented service center.

${ }^{16}$ These benchmarks are from SGB II $\S 44 \mathrm{c}$ paragraph 4 in Bundesgesetzblatt 2011, part I, Nr.23, p.852-891.
} 


\section{Overlooked PEA and debate on benefits}

\subsection{PEA in the post-reform evaluation effort}

An evaluation of all Hartz reforms was foreseen by the law with results to be delivered by the end of 2006. ${ }^{17}$ Overall the reform has enjoyed rather favorable assessment ex post (see e.g. Jacobi and Kluve, 2007; Fitzenberger, 2009, and most recently, Hertweck and Sigrist, 2012). Despite the fact that some of the modules, such as for instance employment-stimulating measures for older workers in the first package, did not completely meet initial expectations, the reform comprised a fair number of successes policies. Within Hartz I, particular merit in reducing unemployment has been attributed to introduction of training vouchers (Schneider and Uhlendorff, 2006). Hartz II has provided an especially strong impact through start-up subsidies (Baumgartner and Caliendo, 2008; Caliendo and Künn, 2011). A positive and significant net effect of Hartz I and II as collections of policies was similarly underlined by Fahr and Sunde (2009) and Klinger and Rothe (2012).

Unlike with Hartz I and II that have generated a good deal of evaluation studies, except of the already mentioned Fahr and Sunde (2009) and Klinger and Rothe (2012), there is no paper known to us that explicitly addresses the restructuring of the Federal Employment Agency (Hartz III). The reason is, most likely, in the nature of the package itself. It deals with macro-aspects of matching effectiveness, whereas the majority of the evaluation studies to date were the reduced-form econometric analyses of micro-data, which makes identification rather difficult. Finally, even Fahr and Sunde (2009) and Klinger and Rothe (2012) are silent about the equilibrium effects. ${ }^{18}$ As a result, the whole power of the reform of the agency was largely overlooked by the major segment of the post-reform evaluation literature.

There also exists a smaller segment of the literature that develops structural equilibrium models capable of pinning down the effect of the reformed agency. Krebs and Scheffel (2013) suggest an equilibrium matching model with ex ante homogeneous workers, consumption and savings decisions and markets for physical and human capital. Krause and Uhlig (2012) consider an equilibrium matching model with ex ante skill heterogeneity of workers, human capital dynamics and endogenous separations. Launov and Wälde (2013) develop an equilibrium matching model with ex ante skill heterogeneity of workers, explicit two-step benefit mechanism, known time limit on UI benefits and endogenous spell-dependence of unemployment duration. All three provide a direct link between the effectiveness of matching and benefit system design on the one hand and the equilibrium unemployment rate on the other hand, allowing straightforward causal interpretation of unemployment changes due to the reform. However this literature also leaves the reform of the PEA unaddressed, concentrating nearly all of its effort on the reduction of benefit generosity under Hartz IV.

\footnotetext{
17 "Vierteljahrshefte zur Wirtschaftsforschung", 2006, 75(3), and "Zeitschrift für ArbeitsmarktForschung", 2006, 39(3/4), have dedicated two special issues to embody the corresponding set of evaluation studies. These were mostly policy-advisory and concentrated predominantly on the effect of the first three packages of the reform because reliable data on the last one were not available yet.

${ }^{18}$ Possibly the closest to recognizing the role of the reform of PEA were Krause and Uhlig (2012) who do have an equilibrium model with the aggregate matching function. Krause and Uhlig (2012) simulate the composite effect of all packages pre-dating the reform of the benefit system, but do not provide any discussion on the impact of PEA. Furthermore, their quantitative results hinge on the assumptions about the direct effect of UA reduction, which we discussin detail in Section 5.2. Krebs and Scheffel (2013) follow the suite.
} 
The analysis of the present paper clearly shows that improving a PEA has a considerable potential and analysis of agencies' effectiveness should not be easily overlooked.

\subsection{The root of diverse results on unemployment benefits}

A good deal of attention paid to the equilibrium effects of reduced generosity of unemployment benefits under Hartz IV has led to a good deal of heterogeneity in evaluation results. Of the observed 3.9 percentage point decline in the unemployment rate, Krause and Uhlig (2012) attribute 2.8 percentage points to Hartz IV. Krebs and Scheffel (2013) find that Hartz IV is responsible only for a 1.4 percentage point reduction. Launov and Wälde (2013) report a 0.1 percentage point reduction at most. The present paper adjusts this upward a bit, though still to a very modest 0.3 percentage points. ${ }^{19}$ Why do we find such a small effect relative to the first two studies? It turns out that the bulk of the answer lies in the assumption about the severity of the benefit cut implied by the reform.

Krebs and Scheffel (2013) implement the switch to the new ALG II system through reducing the replacement rate on previous wage earnings of long-term unemployed from 0.57 to 0.46 , where the latter numbers are borrowed by them from OECD reports. These OECD reports however are too aggregated to reflect the impact of the reform on ex ante heterogeneous workers, ruling out the existence of winners and losers of Hartz IV. Furthermore, if compared to German microdata, such drop in replacement rate appears to be quite big. If we perform the simulation of such a benefit reduction, we predict that Hartz VI is responsible for unemployment rate going down by 0.7 percentage points. ${ }^{20}$ This stops almost exactly halfway between 0.1 percentage points reported by Launov and Wälde (2013) and 1.4 percentage points reported by Krebs and Scheffel (2013). Interestingly, in their Section 6.6.1 by taking a less pronounced reduction of benefit generosity (from 0.57 to just 0.53) Krebs and Scheffel in a similar fashion approach the results of our current paper coming up with 0.7 percentage points decline of the unemployment rate.

Krause and Uhlig (2012) evaluate Hartz IV by removing UA benefits completely. Instead they let an unemployed individual receive a welfare benefit that amounts to $80 \%$ of the lowest pre-reform UA benefit by assumption. This leads to even stronger cuts if compared to Krebs and Scheffel (2013). Table 2 in Krause and Uhlig (2012) shows that welfare benefits after the reform amount to 0.33 of the pre-reform UA benefit for the high-skilled workers and to 0.76 of the pre-reform UA benefit for the low-skilled workers. Again, if we take our own model to simulate the Hartz IV reform using the benefit cut of Krause and Uhlig (2012), we find that Hartz IV explains 2.0 percentage point reduction of the unemployment rate. ${ }^{21}$ This result once again comes close to the reported 2.8 percentage points, the latter also comprising the effect of reduced entitlement to UI.

Thus, with three totally different matching models making fairly close predictions on the

\footnotetext{
${ }^{19}$ Lastly, almost equidistant from Krebs and Scheffel (2013) and Launov and Wälde (2013) is the result of Franz et al. (2012). Their CGE-microsimulation analysis implies the reduction of the unemployment rate by 0.6 percentage points, though the analysis itself is not fully dynamic.

${ }^{20}$ We simulate Hartz IV in a counterfactual absence of the reform of PEA to be consistent with Krebs and Scheffel (2013). Entitlement is kept at pre-reform values to single out the effect of benefits.

${ }^{21}$ Here as well, the simulation of Hartz IV is performed in a counterfactual absence of the reform of PEA to be consistent with Krause and Uhlig (2012). Entitlement is kept at pre-reform values.
} 
effect of the reform conditional on the same input, the central question "which analysis to lend more credibility?" indeed simplifies to a question "how big the benefit cut induced by the Hartz IV reform actually was?". In a way, the fact that the above models coincide in their predictions is good news as it strongly underlines the policy relevance of work of this type. Returning now to the central question, we have to know more on benefits. Did the reform reduce UA payments to the half? Was this reduction even stronger? Or maybe much weaker? We look for the answer to this question in the income data of benefit recipients before and after 2005, at both aggregate and disaggregate levels. OECD (2007) suggests that the average effect of the reduction of UA payments has amounted to just $7 \%$. Goebel and Richter (2007) show that, for Germany as a whole, mean benefits of ALG II recipients in 2005 have become 0.94 to 0.95 of the mean benefits of UA recipients in $2004 .^{22}$ In addition Blos and Rudolph (2005) and Goebel and Richter (2007) emphasize that some of ALG II recipients have even improved their income position as a result of the reform $(1 / 2$ and $1 / 3$ of all recipients, respectively). These data stand in contrast with strong cuts taken up by Krebs and Scheffel (2013) and Krause and Uhlig (2012).

Following this data-driven approach, we define the benefit reduction due to Hartz IV as mean ALG II payments after 2005 relative to mean UA payments before 2005. Although comparison of means does not deliver the exact treatment effect of Hartz IV on benefits as an outcome variable, looking at these data still provides the order of magnitude for the change in benefit payments. As expected in light of descriptive findings, these changes can hardly be called substantial. In tab. A.2 we show them for all the skill- and regional groups in our analysis. To draw a parallel to Krause and Uhlig (2012), if we view high- and medium-skilled workers as one group, benefit reduction due to Hartz IV in our data is approximately 0.93 of the original UA benefit, instead of 0.33 in their calibration. For the low-skilled workers ALG II has even exceeded the former UA benefits, marking approximately 1.17 more than the original UA level, in place of 0.76 reduction of Krause and Uhlig (2012).

Summarizing, differences in the predictions of the effects of the Hartz IV reform to very large extent result from differences in the assumptions about severity of the benefit cut exercised by this reform. As modest numbers of an average benefit reduction under 10\%, along with existence of winners and losers, appear empirically more convincing than the assumption of extreme cuts, we claim that very small effect of Hartz IV on the reduction of the unemployment rate is most likely its true effect.

To conclude this discussion, if we want to understand why Krause and Uhlig (2012) obtain such a big reduction in benefits the following explanation appears plausible. In their prereform steady state, Krause and Uhlig (2012) obtain the distribution of benefits as a function of the distribution of skills. Each skill level has an idiosyncratic random productivity which enters the production function. This skill-specific productivity influences the equilibrium wage and, via the statutory replacement rates, ultimately the UI and UA benefit levels. As productivities are drawn form the distribution with non-overlapping supports ${ }^{23}$ equilibrium wages of the high-skilled become more than twice as big as those of the low-skilled. This leads to the same discrepancy between UA benefits of different skills and to even higher

\footnotetext{
${ }^{22}$ Goebel and Richter (2007) also have a detailed breakdown for East and West as well as for the deciles of income distribution; see their tab. 3 on page 757 .

${ }^{23}$ Productivity is uniformly distributed on [0.5,1.5] for low-skilled and [1.5,2.5] for high-skilled; see Krause and Uhlig (2012), page 70.
} 
discrepancy between UA and welfare benefits. As a result, via particular distributional assumptions for productivity one can get a fairly strong simulated effect of the reform.

\section{Conclusions}

In this paper we analyze two different policies aimed at reducing unemployment. One is the standard reduction of allegedly generous unemployment benefits. Another is the improvement of operating effectiveness of a public employment agency that arises as a result of internal reorganization. The first policy addresses search incentives of an unemployed worker without affecting the degree of information frictions in the market. The second, to the contrary, reduces the degree of information frictions. We evaluate both these policies using a unique setup of the recent comprehensive labour market reform in Germany: the Hartz reform of 2003-2005. Our evaluation is carried out in a structurally estimated equilibrium search model. The model directly maps the change in the benefit system, as defined by the legislation, and the change in operating effectiveness of the public employment agency, as estimated in the literature, into the response of the equilibrium unemployment rate.

We find that improved effectiveness of public employment agency has substantially contributed to the reduction of the equilibrium unemployment rate, explaining about $34 \%$ of the difference between the pre-reform and post-reform steady states. The reduction of benefit generosity, which foresaw shortening of entitlement period to unemployment insurance and moderate cuts of unemployment assistance benefits, has brought in contrast a very modest result. Its share in the difference between pre- and post-reform equilibrium unemployment barely exceeds $7 \%$. We also discover that although the German reform of public employment agency was a success, not any increase in effectiveness of the agency should immediately result in lower unemployment. Once it comes to changes in effectiveness that differ between short- and long-term unemployed, the opposing productivity and incentive effects on shortterm unemployed may as well lead to a rise in unemployment. From this perspective the agency reform in Germany was quite fine tuned, comprising differing impacts on short- and long-term unemployed and still leading to sizeable unemployment reduction.

Our analysis makes two main contributions. First, we discover a great unemploymentreducing potential for typical welfare states. It lies in making public employment agencies more effective. There exists a rich literature that addresses different labour market institutions of a welfare state and analyzes how reforming these institutions can help us reduce unemployment. Unemployment compensation systems, trade unions, labour taxes or subsidies and employment protection are all among the most frequently analyzed institutions. Surprising as it is, in the long list of institutions one cannot find the public employment agency itself. With our findings that over $1 / 3$ of the post-reform decline in unemployment can be attributed to their reorganization, public employment agencies and their modernization must not be overlooked by policy makers and by academic researchers.

Second, we show that within a class of search and matching models three very different models of one and the same unemployment benefit reform can generate relatively close predictions, provided that all of them take a given benefit reduction as a common basis for simulation. Thus, correct assessment of the employment effect of the reform appears to be not so much the question of the choice of modelling device, but rather a question of picking 
the right discrepancy between the pre- and post-reform benefits. We choose to be guided by the data and the existing descriptive literature on the change in unemployment assistance as a part of the Hartz reforms in Germany. These data tell us that what can otherwise be considered a typical benefit reduction, is barely capable of delivering an economically significant result. Given the amount of public debates that were surrounding the reduction of benefit generosity we also think that cuts big enough to substantively curtail unemployment lie very likely well outside the range of possible political compromise.

\section{Appendix}

\subsection{Data}

Table A.1 reports parameters required to simulate the model and provides the complete characterization of the steady state before any reform.

\begin{tabular}{|c|c|c|c|c|c|c|c|}
\hline & & high & $\begin{array}{l}\text { West } \\
\text { medium }\end{array}$ & low & high & $\begin{array}{c}\text { East } \\
\text { medium }\end{array}$ & low \\
\hline \multirow{2}{*}{$\begin{array}{l}\text { observed } \\
\text { parameters }\end{array}$} & \multirow{2}{*}{$\begin{array}{l}\pi(k) \\
\pi_{k}^{U I}\end{array}$} & 0.1989 & 0.4094 & 0.1688 & 0.0730 & 0.1202 & 0.0297 \\
\hline & & 0.3913 & 0.5068 & 0.3696 & 0.6757 & 0.7023 & 0.4412 \\
\hline \multirow{2}{*}{$\begin{array}{l}\text { policy } \\
\text { parameters }\end{array}$} & \multirow{2}{*}{$\begin{array}{l}\bar{s}_{k} \\
\tilde{b}_{U A, k}\end{array}$} & 15 & 11 & 11 & 12 & 12 & 13 \\
\hline & & 1109 & 727 & 588 & 998 & 737 & 548 \\
\hline \multirow{4}{*}{$\begin{array}{l}\text { estimated and } \\
\text { predicted parameters }\end{array}$} & $\lambda_{k}$ & 0.0055 & 0.0080 & 0.0124 & 0.0139 & 0.0203 & 0.0282 \\
\hline & $\eta_{0, k}$ & 0.0189 & 0.0224 & 0.0204 & 0.0268 & 0.0360 & 0.0314 \\
\hline & $A_{k}$ & 2155 & 1473 & 1368 & 2130 & 1588 & 1276 \\
\hline & $\gamma_{k}$ & 15633 & 14136 & 13916 & 27563 & 22464 & 8193 \\
\hline \multirow{5}{*}{$\begin{array}{l}\text { equilibrium } \\
\text { values }\end{array}$} & $w_{k}$ & 1705 & 1118 & 905 & 1535 & 1134 & 843 \\
\hline & \multirow{2}{*}{$\begin{array}{ll}\theta_{k} & \mathrm{p}): \\
\mathrm{c}):\end{array}$} & 0.46 & 0.27 & 0.16 & 0.11 & 0.08 & 0.19 \\
\hline & & 0.37 & 0.21 & 0.13 & 0.09 & 0.06 & 0.14 \\
\hline & \multirow{2}{*}{$\begin{array}{ll} & \mathrm{p}): \\
u_{k} & \mathrm{c}):\end{array}$} & $4.6 \%$ & $7.4 \%$ & $15.9 \%$ & $15.1 \%$ & $19.1 \%$ & $22.1 \%$ \\
\hline & & $5.1 \%$ & $8.1 \%$ & $17.5 \%$ & $16.5 \%$ & $20.9 \%$ & $24.1 \%$ \\
\hline \multirow{2}{*}{$\begin{array}{l}\text { estimated } \\
\text { aggregate parameters }\end{array}$} & $\alpha$ & 0.4203 & $\pi^{U A}$ & 0.2398 & \multirow[t]{2}{*}{$\nu$} & \multirow[t]{2}{*}{1.4438} & \\
\hline & $\sigma$ & 0.7808 & $\pi^{\chi}$ & 0.9228 & & & \\
\hline \multirow{4}{*}{$\begin{array}{l}\text { aggregate } \\
\text { equilibrium values }\end{array}$} & \multirow{4}{*}{$\begin{array}{ll}\kappa^{\mathrm{p}):} & \mathrm{c}): \\
& \mathrm{p}): \\
\left.u^{\mathrm{c}}\right):\end{array}$} & 0.0225 & \multirow{4}{*}{\multicolumn{2}{|c|}{$\begin{array}{l}\text { exogenous } \\
\text { parameters }\end{array}$}} & \multirow{4}{*}{$\begin{array}{l}\rho \\
\beta\end{array}$} & \multirow{4}{*}{$\begin{array}{l}2.4 \% \text { p.a. } \\
0.5\end{array}$} & \\
\hline & & 0.0244 & & & & & \\
\hline & & $10.7 \%$ & & & & & \\
\hline & & $11.7 \%$ & & & & & \\
\hline
\end{tabular}

Notes: Above, “p):" stands for predicted and “c):" stands for calibrated pre-reform steady state

Table A.1 Characteristics of the pre-reform steady state 
Sources for this table are the GSOEP (www.gsoep.de) for wage and benefit data along with all group characteristics; the IAB (www.iab.de) for vacancy and unemployment data and Launov and Wälde (2013) for the sample taken from GSOEP and all the structural parameters. The skill distribution $\{\pi(k)\}_{k=1}^{K}$ in the economy relates to the sample taken from the entire population of working age individuals. The rest of the observed data, except of labour market tightness, stems from the flow sample of entrants into full-time employment and unemployment between 01.2001 and 12.2003.

All monetary values are in Euros of 2005. Reported UA benefits $\tilde{b}_{U A, k}$ are conditional on eligibility to UI benefits (an event happening with probability $\pi_{k}^{U I}$ ) and on passing the means test upon expiration of entitlement to UI (an event happening with probability $\pi^{U A}$ ). Expected benefit $b_{U A, k}$ used in the simulation is therefore defined as $b_{U A, k} \equiv \pi_{k}^{U I} \pi^{U A} \tilde{b}_{U A, k}$. The statutory replacement rate is set to 0.65 of the average net wage of previous employment, such that $\tilde{b}_{U A, k} \equiv 0.65 * w_{k}$. Entitlement length $\bar{s}$ is computed using the observed duration of the contribution period in the last employment spell and age-dependent rules before Hartz IV.

Parameters $\left\{\lambda_{k}, \eta_{0, k}\right\}_{k=1}^{K}$ and $\left\{\alpha, \sigma, \pi^{U A}, \pi^{\chi}, \nu\right\}$ are structurally estimated. For methodological discussion of the prediction of parameters $\left\{A_{k}, \gamma_{k}\right\}_{k=1}^{K}$ and of the equilibrium solution for $\left\{w_{k}, u_{k}, \theta_{k}\right\}_{k=1}^{K}$ and $\kappa$ see Launov and Wälde (2013).

Table A.2 reports changes to benefits and entitlement as a consequence of Hartz IV. All values in this table are computed as described on page 18 .

\begin{tabular}{lcccccc}
\hline \hline & high & $\begin{array}{c}\text { West } \\
\text { medium }\end{array}$ & low & high & $\begin{array}{c}\text { East } \\
\text { medium }\end{array}$ & low \\
\hline \hline ALG II as a share of UA & 0.95 & 0.95 & 1.15 & 0.70 & 0.95 & 1.3 \\
Entitlement cut (months) & 3 & 1 & 1 & 1 & 2 & 2 \\
\hline
\end{tabular}

Table A.2 Specification of the Hartz IV reform

\subsection{The literature on Hartz reforms}

In principle, all labour market regulations and their changes are documented in the corresponding laws ('Sozialgesetzbüchern'). As a starting point on labour market policy and how it is encoded in the law, see Keller and Henneberger (2010). Considering e.g. the first and third packages of the reform, the basic law is "SGB III - Arbeitsförderung" (Bundesgesetzblatt 1997, Teil I, Nr.20, p.595-689). Amendments to this law through Hartz I are in "Erstes Gesetz für Moderne Dienstleistungen am Arbeitsmarkt" (Bundesgesetzblatt 2002, Teil I, Nr.87, p.4607-4616). Changes induced by Hartz III are in "Drittes Gesetz für Moderne Dienstleistungen am Arbeitsmarkt" (Bundesgesetzblatt 2003, Teil I, Nr.65, p.2849-2886). Distilling out the changes due to the Hartz reforms from reading the various paragraphs is a research project on its own. This is why we rely on the literature.

The existing literature is huge and ranges from newspaper to scientific articles. Most of these articles have a strong policy and political orientation. Here is a list of articles on which 
we base our summary in the main text. Kaltenborn, Knerr and Schiwarov (2006a) provide a summary of the evaluations of Hartz I, II and III. The long version is the report by the Bundesregierung (2005). An even more extensive version is Bundesministerium für Arbeit und Soziales (2006). Based on the latter, Kaltenborn, Knerr and Schiwarov (2006b) provide a list of various measures (see their table 1).

Heyer, Koch, Stephan and Wolff (2012) provide an overview of active labour market policies. Jacobi and Kluve (2007) work out the core elements of the Hartz reforms. Weise (2011), the head of the "Bundesagentur für Arbeit", provides a clear description of the effects of Hartz III with respect to the reorganization of the German PEA. Schuetz and Oschmiansky (2006) also emphasize the importance of the reorganization of the German PEA.

A website providing a good overview (despite its not being completely up to date) is WIPOL (2006). While all of this literature is in German, the papers on Hartz reforms we cite in the main text have a short summary of institutional details as well.

\subsection{Robustness}

Here we present the same simulation of the reform as in Section 4.1.2, performed by means of exact calibration targeted at the observed unemployment rate of $11.71 \%$.

\begin{tabular}{|c|c|c|c|c|c|}
\hline & & \multicolumn{2}{|c|}{ Identical impact } & \multicolumn{2}{|c|}{ Differing impact } \\
\hline & & $\begin{array}{c}\text { absolute } \\
\text { reduction (ppt) }\end{array}$ & $\begin{array}{c}\text { explained } \\
\text { reduction }(\%)\end{array}$ & $\begin{array}{c}\text { absolute } \\
\text { reduction (ppt) }\end{array}$ & $\begin{array}{c}\text { explained } \\
\text { reduction }(\%)\end{array}$ \\
\hline (1) & Hartz III & 1.95 & $49.87 \%$ & 1.50 & $38.36 \%$ \\
\hline (2) & Hartz IV & 0.07 & $1.79 \%$ & 0.07 & $1.79 \%$ \\
\hline (3) & Hartz III \& IV & 2.05 & $52.43 \%$ & 1.82 & $46.55 \%$ \\
\hline (4) & $\begin{array}{l}\text { Hartz IV given } \\
\text { Hartz III }{ }^{\mathrm{a})}\end{array}$ & 0.10 & $2.56 \%$ & 0.32 & $8.18 \%$ \\
\hline (5) & $\begin{array}{l}\text { Interaction of } \\
\text { Hartz III and } \\
\text { Hartz IV }\end{array}$ & 0.03 & $0.77 \%$ & 0.25 & $6.39 \%$ \\
\hline
\end{tabular}

${ }^{a)}$ Line (3) minus line (1) b) Line (4) minus line (2)

Table A.3 Simulated reduction of the unemployment rate (calibration)

Direct comparison with tab. 1 shows that results stated in Section 4.1.2 are hardly affected by the choice of a particular method to simulate the reforms. 


\section{References}

Albrecht, J., and S. Vroman (2005): "Equilibrium Search with Time-Varying Unemployment Benefits," Economic Journal, 115, 631-648.

Baumgartner, H., and M. Caliendo (2008): "Turning Unemployed into Self-Employed: Effectiveness of Two Start-Up Programmes," Oxford Bulletin of Economics and Statistics, $70,347-373$.

Bentolila, S., P. Cahuc, J. Dolado, and T. Le Barbanchon (2012): "Two-Tier Labour Markets in the Great Recession: France versus Spain," The Economic Journal, 122, F155-F187.

Bhagwati, J. (1958): "Immiserizing Growth: A Geometrical Note," Review of Economic Studies, 25(3), 201-205.

Blau, D., and P. Robins (1990): "Job Search Outcomes for the Employed and Unemployed," Journal of Political Economy, 98, 637-655.

Blau, F., and L. Kahn (1999): "Institutions and Laws in the Labor Market," in Handbook of Labor Economics, ed. by O. Ashenfelter, and D. Card, vol. 3a, chap. 25, pp. 1399-1461. Elsevier Science B.V.

Blos, K., and H. Rudolph (2005): "Verlierer, aber auch Gewinner," IAB Kurzbericht, 17, $1-6$.

Boeri, T., and M. Burda (2009): "Preferences for Collective versus Individualised Wage Setting," The Economic Journal, 119, 1440-1463.

Bundesagentur für Arbeit (2013): "SGB II - Jahresbericht 2012," Bundesagentur für Arbeit.

Bundesministerium für Arbeit und Soziales (2006): "Die Wirksamkeit moderner Dienstleistungen am Arbeitsmarkt," Bericht 2006 des Bundesministeriums für Arbeit und Soziales zur Wirkung der Umsetzung der Vorschläge der Kommission Moderene Dienstleistungen am Arbeitsmarkt.

Bundesregierung (2005): "Bericht 2005 der Bundesregierung zur Wirksamkeit moderner Dienstleistungen am Arbeitsmarkt," Bundesregierung.

Cahuc, P., and T. Le Barbanchon (2010): "Labor Market Policy Evaluation in Equilibrium: Some Lessons of the Search and Matchnig Model," Labour Economics, 17, 196-205.

Cahuc, P., and E. Lehmann (2000): "Should Unemployment Benefits Decrease with the Unemployment Spell?," Journal of Public Economics, 77, 135-153.

Cahuc, P., and F. Malherbet (2004): "Unemployment Compensation Finance and Labor Market Rigidity," Journal of Public Economics, 95, 481-501.

Caliendo, M., and S. Künn (2011): "Start-Up Subsidies for the Unemployed: Long-Term Evidence and Effect Heterogeneity," Journal of Public Economics, 95, 311-331. 
Carling, K., B. Holmlund, and A. Vejsiu (2001): "Do Benefit Cuts Boost Job Finding? Sweedish Evidence from the 1990s," The Economic Journal, 111, 766-790.

Chéron, A., and F. Langot (2010): "On-the-Job Search Equilibrium with Endogenous Unemployment Benefits," Labour Economics, 17, 383-391.

Coles, M., and A. Masters (2006): "Optimal Unemployment Insurance in a Matching Equilibrium," Journal of Labor Economics, 24, 109-138.

Coles, M., and E. Smith (1998): "Marketplaces and Matchnig," International Economic Review, 39, 239-254.

Fahr, R., and U. Sunde (2009): "Did the Hartz Reforms Speed-Up the Matching Process? A Macro-Evaluation Using Empirical Matching Functions," German Economic Review, 10, 284-316.

Fitzenberger, B. (2009): "Nach der Reform ist vor der Reform? Eine arbeitsökonomische Analyse ausgewählter Aspekte der Hartz-Reformen," in Reformen für Deutschland Die wichtigsten Handlungsfelder aus ökonomischer Sicht, ed. by G. Schultze, pp. 21-48. Schäffer-Poeschel Verlag.

Flinn, C. (2006): "Minimum Wage Effects on Labor Market Outcomes under Search, Matching, and Endogenous Contact Rates," Econometrica, 74, 1013-1062.

Fougère, D., J. Pradel, and M. Roger (2009): "Does the Public Employment Service Affect Search Effort and Outcomes?," European Economic Review, 53, 846-869.

Franz, W., N. Guertzgen, S. Schubert, and M. Clauss (2012): "Assessing the Employment Effects of the German Welfare Reforn - An Integrated CGE-Microsimulation Approach," Applied Economics, 44, 2403-2421.

Geerdsen, L. (2006): "Is there a Threat Effect of Labour Market Programmes? A Study of ALMP in the Danish UI System," The Economic Journal, 116, 738-750.

Goebel, J., and M. Richter (2007): "Nach der Einführung von Arbeitslosengeld II: Deutlich mehr Verlierer als Gewinner unter den Hilfeempfängern," DIW Wochenbericht, 74, 753761.

Graversen, B., and J. van Ours (2008): "How to Help Unemployed Fnd Jobs Quickly: Experimental Evidence from a Mandatory Activation Program," Journal of Public Economics, 92, 2020-2035.

Gregg, P., and B. Petrongolo (2005): "Stock-Flow Matchnig and the Performance of the Labor Market," European Economic Review, 49, 1987-2011.

Hertweck, M., and O. Sigrist (2012): "The Aggregate Effects of the Hartz Reforms in Germany," University of Konstanz, Working Paper 2012-38. 
Heyer, G., S. Koch, G. Stephan, and J. Wolff (2012): "Evaluation der aktiven Arbeitsmarktpolitik: Ein Sachstandsbericht für die Instrumentenreform 2011," Zeitschrift für ArbeitsmarktForschung, 45, 41-62.

Holzer, H. (1988): "Search Method Use by Unemplyoed Youth," Journal of Labor Economics, $6,1-20$.

Immervoll, H., H. Kleven, C. Kreiner, and E. Saez (2007): "Welfare Reform in European Countreis: A Microsimulation Analysis," The Economic Journal, 117, 1-44.

Jacobi, L., and J. Kluve (2007): "Before and After the Hartz Reforms: The Performance of Active Labour Market Policy in Germany," Zeitschrift für ArbeitsmarktForschung, 40, 45-64.

Jung, P., and M. Kuhn (2013): "Labor Market Institutions and Worker Flows: Comparing Germany and the U.S.," The Economic Journal, forthcoming.

Kaltenborn, B., P. Knerr, and J. Schiwarov (2006a): "Hartz: Bilanz der Arbeitsmarkt- und Beschäftigungspolitik," Blickpunkt Arbeit und Wirtschaft, 12, 1-7.

(2006b): "Hartz: Förderstrukturen," Blickpunkt Arbeit und Wirtschaft, 11, 1-6.

Keller, B., and F. Henneberger (2010): "Arbeitsmarktpolitik," in Gabler Wirtschaftslexikon, pp. 177-183. Springer Gabler Verlag, 17th edn., online: http://wirtschaftslexikon.gabler.de/Archiv/974/arbeitsmarktpolitik-v13.html.

Klinger, S., and T. Rothe (2012): "The Impact of Labour Market Reforms and Economic Performance on the Matching of the Short-Term and Long-Term Unemployed," Scottish Journal of Political Economy, 59, 90-114.

Krause, M., and H. Uhlig (2012): "Transitions in the German Labor Market: Structure and Crisis," Journal of Monetary Economics, 59, 64-79.

Krebs, T., and M. Scheffel (2013): "Macroeconomic Evaluation of Labor Market Reform in Germany," Discussion Paper.

Launov, A., and K. Wälde (2013): "Estimating Incentive and Welfare Effects of NonStationary Unemployment Benefits," International Economic Review, forthcoming.

Lehmann, E., and B. van der Linden (2007): "On the Optimality of Search Matching Equilibrium When Workers Are Risk Averse," Journal of Public Economic Theory, 9, 867-884.

L'Haridon, O., and F. Malherbet (2009): "Employment Protection Reform in Search Economies," European Economic Review, 53, 255-273.

Ljungqvist, L., and T. Sargent (1998): "The European Unemployment Dilemma," Journal of Political Economy, 106, 514-550.

(2008): “Two Questions about European Unemployment," Econometrica, 76, 1-29. 
Mortensen, D., and C. Pissarides (1999): "Unemployment Responses to 'Skill-Biased' Technology Shocks: The Role of Labour Market Policy," The Economic Journal, 109, 242-265.

Nickell, S., and R. Layard (1999): "Labour Market Institutions and Economic Performance," in Handbook of Labor Economics, ed. by O. Ashenfelter, and D. Card, vol. 3c, chap. 46, pp. 3029-3084. Elsevier Science B.V.

Nickell, S., and J. van Ours (2000): "The Netherlands and the United Kingdom: A European Unemployment Miracle?," Economic Policy, 15, 137-180.

OECD (2007): "Benefits and Wages 2007," OECD Indicators.

Petrongolo, B. (2009): "The Long-Term Effects of Job Search Requirements: Evidence from the UK JSA Reform," Journal of Public Economics, 93, 1234-1253.

Petrongolo, B., and C. Pissarides (2001): "Looking into the Black Box: A Survey on the Matching Function," Journal of Economic Literature, 39, 390-431.

Pissarides, C. (1979): "Job Matchings with State Employment Agencies and Random Search," The Economic Journal, 89, 818-833.

Plesca, M. (2010): “A General Equilibrium Evaluation of the Employment Service," Journal of Human Capital, 4, 274-329.

Postel-Vinay, F., and J.-M. Robin (2002): "Equilibrium Wage Dispersion with Worker and Employer Heterogeneity," Econometrica, 70, 2295-2350.

Pries, M., and R. Rogerson (2005): "Hiring Policies, Labor Market Institutions and Labor Market Flows," Journal of Political Economy, 113, 811-839.

Røed, K., and L. Westlie (2012): "Unemployment Insurance in Welfare States: The Impacts of Soft Duration Constraints," Journal of the European Economic Association, 10, 518554 .

Schneider, H., and A. Uhlendorff (2006): "Die Wirkung der Hartz-Reform im Bereich der beruflichen Weiterbildung," Zeitschrift für ArbeitsmarktForschung, 39, 477-490.

Schütz, H., and F. Oschmiansky (2006): "Arbeitsamt war gestern: Neuausrichtung der Vermittlungsprozesse in der Bundesagentur für Arbeit nach den Hartz-Gesetzen," Zeitschrift für Sozialreform, 52, 5-28.

Weber, A., and H. Mahringer (2008): "Choice and Success of Job Search Methods," Empirical Economics, 35, 153-178.

Weise, F.-J. (2011): "Der Umbau der Bundesanstalt/Bundesagentur für Arbeit zum modernen Dienstleister," Vierteljahrshefte zur Wirtschaftsforschung, 80, 67-78.

WIPOL (2006): "Hartz-Evaluierung," http://www.wipol.de/hartz/evaluierung.htm. 
Yashiv, E. (2004): "Macroeconomic Policy Lessons of Labor Market Frictions," European Economic Review, 48, 259-284.

Yavaş, A. (1994): "Middlemen in Bilateral Search Markets," Journal of Labor Economics, $12,406-429$. 